\title{
LAS MIGRACIONES INTERNAS DE LOS EXTRANJEROS EN ESPAÑA: DINÁMICAS ESPACIALES RECIENTES BAJO EL IMPACTO DE LA CRISIS ${ }^{1}$
}

\author{
Fernando Gil-Alonso* \\ Jordi Bayona-i-Carrasco** \\ Isabel Pujadas Rúbies* \\ * Departament de Geografia Humana. Universitat de Barcelona \\ ${ }^{* *}$ Centre d'Estudis Demogràfics \\ fgil@ub.edu ; jordibayona@ub.edu ; ipujadas@ub.edu
}

\section{RESUMEN}

El artículo analiza las modificaciones que han experimentado los patrones de migración interna de la población extranjera a causa de la crisis económica, y los compara con los existentes antes de ésta. Los resultados de la investigación, utilizando la Estadística de Variaciones Residenciales, muestran: 1) el descenso de la importancia en términos absolutos y relativos de las migraciones internas de los extranjeros; 2) la existencia de diferencias remarcables en las tasas de migración interna, y en la importancia de la caída, según la nacionalidad; y 3) cambios importantes en los patrones geográficos preexistentes respecto a las provincias emisoras y receptoras de migrantes extranjeros.

Palabras clave: Migraciones internas; población extranjera; crisis económica; pautas territoriales; España.

Fecha de recepción: octubre 2013.

Fecha de aceptación: julio 2014.

1 Este trabajo se ha realizado en el marco del proyecto de I+D "Las nuevas ciudades españolas. El impacto espacial de las dinámicas demográficas recientes en las grandes áreas urbanas españolas en un contexto de crisis" (CSO2011-24680), dirigido por la Dra. Isabel Pujadas y financiado por el Ministerio de Ciencia e Innovación. Los autores son además miembros del grupo de investigación consolidado Territorio, Población y Ciudadanía, reconocido por la Generalitat de Cataluña (GRC_2014SGR380) y dirigido por la Dra. Isabel Pujadas. 


\begin{abstract}
The article analyses foreign population's internal migration pattern changes due to the effect of the economic crisis. Estadística de Variaciones Residenciales (Residential Variations Statistics) flow data are used to this end. Main results shows that: 1) due to the crisis, both absolute and relative foreign internal migration figures have significantly decreased; 2) there are remarkable differences among foreign citizen groups both in terms of internal migration rates and regarding the importance of the decline; and 3) geographical patterns have been deeply modified, as some of the provinces that attracted internal migrants before the crisis now expel them, and vice versa.
\end{abstract}

Keywords: Internal migration, foreign population, economic crisis, territorial patterns, Spain.

\title{
I. INTRODUCCIÓN
}

La etapa de intensos flujos migratorios internacionales que España experimentó durante los años de fuerte crecimiento económico llegó a su fin a partir del año 2008 como consecuencia de la grave crisis económica de carácter global, que en nuestro país se ha visto acentuada por el pinchazo de la «burbuja inmobiliaria». Emerge desde entonces una nueva situación migratoria caracterizada por un descenso significativo de las inmigraciones de extranjeros (Gil-Alonso et al., 2013) y un aumento progresivo de las emigraciones que hacen que España, según las estimaciones demográficas del INE, tenga un saldo migratorio negativo con el exterior desde el año 2010 (INE, 2013). Como cabe esperar, una situación de crisis tan profunda como la actual obliga a revisar muchos de los parámetros establecidos durante los últimos años, en especial si hacemos referencia a la población extranjera, una de las más afectadas por las elevadas tasas de desempleo que experimenta el país.

Las migraciones internas tienen como efecto una redistribución de la población, con un impacto demográfico y social sobre las regiones o municipios de origen y de destino, que en un contexto demográfico como el actual, caracterizado por una baja fecundidad y una mortalidad controlada, adquieren mayor visibilidad como generadoras de las dinámicas demográficas de crecimiento o decrecimiento más importantes. Los migrantes, por su lado, responden a perfiles sociodemográficos diferentes en función del tipo de migración y de su origen o destino. En el caso de la población extranjera, la migración interna significa una segunda o posterior migración después de su llegada a España, con una readaptación al mercado laboral o residencial. En momentos como los actuales, de fuerte crisis económica e inestabilidad laboral, especialmente de la población extracomunitaria -que experimenta tasas de desempleo incluso más elevadas que las ya altas que sufre la población española (Vidal-Coso y Gil-Alonso, 2013)-, es de esperar cambios sustanciales en sus patrones migratorios, ya sea en forma de nuevas migraciones atendiendo a las posibilidades del mercado laboral, como en posibles aumentos de la permanencia, y por lo tanto, con un decrecimiento de la movilidad.

Estos son los objetivos de este trabajo, ofrecer un retrato reciente de la evolución de la migración interna de los extranjeros en España, con la hipótesis de partida de que la cri- 
sis debe haber modificado las tendencias previas. De manera más específica, la investigación pretende responder a las preguntas siguientes: ¿cómo ha afectado la crisis a los flujos migratorios internos?; ¿ha causado un incremento o un descenso de sus tasas de migración interna?; ¿lo ha hecho en todas las nacionalidades por igual?; ¿siguen siendo los ciudadanos extranjeros más móviles que los españoles, como antes de la crisis?; ¿qué provincias anteriormente inmigratorias se han transformado en emigratorias, y viceversa?; ¿continúan existiendo diferencias en los patrones geográficos de los distintos grupos de nacionalidades? Para contestar estas preguntas contamos con los datos publicados por el Instituto Nacional de Estadística (INE) de dos tipos de fuentes ya clásicas en este tipo de análisis: el Padrón continuo -que ofrece información de los stocks de población extranjera y a su vez nos permite calcular tasas de migración- y, sobre todo, una fuente derivada de la anterior que mide los flujos migratorios externos e internos y ofrece información socio-demográfica desagregada territorialmente sobre los protagonistas de dichas migraciones. Se trata de las Estadísticas de Variaciones Residenciales (EVR), que en este artículo analizaremos en profundidad para dos periodos sucesivos: 2004-2007, que coincide con una etapa de boom económico y creciente movilidad, y 2008-2011, donde se observan ya los efectos de la crisis.

Este trabajo se inicia con el marco teórico y estado de la cuestión -apartado II-, que repasa los esfuerzos conceptuales y metodológicos que se han hecho, a nivel internacional, para estimar el impacto de la crisis sobre los flujos migratorios, así como las investigaciones recientes que en España se han hecho sobre este tema, particularmente sobre las migraciones internas. A continuación, tras una presentación de las fuentes estadísticas (III), se describe brevemente la evolución reciente respecto a las entradas de extranjeros y la evolución de sus stocks en nuestro país (IV). Esa información permite contextualizar los principales resultados de la investigación, que se muestran en el siguiente apartado (V). Éste se centra en analizar las pautas de movilidad interna de la población extranjera y las consecuencias que la crisis ha tenido en ellas, tanto respecto a su intensidad y características demográficas (sexo, edad y nacionalidad) como respecto a sus patrones espaciales. Finalmente, los principales resultados se presentan y discuten en las conclusiones (VI).

\section{MARCO TEÓRICO Y ESTADO DE LA CUESTIÓN}

\section{II.1. Aproximaciones teóricas a las consecuencias de la crisis sobre las migraciones}

En la actualidad, el conocimiento existente sobre el impacto de la crisis económica global sobre los flujos migratorios internacionales e internos se encuentra todavía en un estadio fragmentario e inconcluso, debido a dos hechos: 1) el período transcurrido desde el inicio de la crisis en los Estados Unidos a finales de 2007 no permite aún tener la suficiente perspectiva histórica, teniendo en cuenta además el retraso en la publicación de estadísticas comparativas a nivel mundial; y 2) la propia recesión ha adoptado a lo largo de estos años recientes diversas características y fases, con importantes variaciones entre países (Reyneri, 2009). De esta forma, lo que empezó durante los años 2007 y 2008 como una crisis de carácter financiero, se transmutó en una profunda crisis económica a la que se sumó -especialmente en países como España- la explosión de la llamada «burbuja inmobiliaria», cuyas consecuencias se transmitieron después a otros sectores, como la industria. Finalmente, la crisis de la deuda monetaria de 
los años 2011-2013, que afectó especialmente a los países del sur de Europa, llevó a la implantación de fuertes políticas de ajuste de las cuentas públicas que causaron un importante impacto sobre el consumo -por lo tanto, sobre el sector servicios- y el empleo público.

Las primeras reflexiones sobre la repercusión de la crisis en los flujos migratorios aparecen en 2009, cuando el impacto de la recesión ya empezaba a ser evidente. Stephen Castles organizó ese año un Simposio Virtual para recolectar contribuciones de expertos de todo el mundo. A partir de esas informaciones, Castles (2009) dedujo que las migraciones por motivos laborales habían experimentado una sensible caída, aunque no se habían llegado a paralizar, mientras que otras formas de migración (reagrupación familiar, jubilación, ejecutivos o demandas de asilo) habían sido mucho menos afectadas.

La evidente desaceleración, en los países de destino, del crecimiento de los stocks de migrantes extranjeros - de una tasa anual de 2,3\% en el periodo 2000-2010 a 1,6\% entre 2010 y 2013 (Naciones Unidas, 2013) - no vino sin embargo acompañada, en los primeros años de recesión, por un retorno significativo de inmigrantes ni en Europa ni en Estados Unidos (Castles, 2009 y 2011; Castles y Miller, 2010). El miedo a no poder regresar en un futuro debido a los crecientes controles migratorios, y las escasas perspectivas de trabajo en los países de origen, parecían estar detrás de esta tendencia. En este sentido, como indican Papademetriou y Terrazas (2009), los flujos de retorno parecen estar más vinculados con cambios en la situación de desarrollo económico, político y social de los países de origen, y con las posibilidades de circulación migratoria, que con las circunstancias económicas de los países receptores. Así, incluso en caso de fuertes privaciones materiales, muchos inmigrantes prefieren resistir los efectos de la crisis en el país de destino, con la esperanza que una futura recuperación económica generará nuevos puestos de trabajo. Sólo cuando las circunstancias económicas en sus países de origen han experimentado sustanciales mejoras, o cuando se garantiza a los migrantes una reemigración futura, éstos regresan en un número significativo (sería el caso de los polacos que migraron a Gran Bretaña e Irlanda). Cuando estas dos condiciones no existen, el retorno no se erige como una opción popular (Ratha et al., 2009), como muestran los pobres resultados que las ofertas de incentivos a inmigrantes desempleados para facilitar su regreso han obtenido en países como España o la República Checa. Y aquellos que retornan más son los que los países de destino querrían retener: los que tienen suficiente formación, aptitudes y perspectivas, así como un estatus legal seguro que les permitirá volver al país de destino cuando el mercado laboral mejore.

Otras hipótesis que se fijan en las características de los migrantes y de los mercados de trabajo en los países de destino han sido enunciadas por diversos autores para explicar por qué no se han dado masivos retornos (Awad, 2009; Fix et al., 2009; Ghosh, 2009; Dobson et al., 2009; Fielding, 2010; Castles, 2011). En efecto, las evidencias recogidas muestran que la mayoría de los migrantes laborales tienen similares características demográficas que los trabajadores autóctonos más vulnerables durante las recesiones, esto es, son relativamente jóvenes, con bajo nivel educativo y tienen una situación precaria en el mercado de trabajo. Es decir, están sobrerrepresentados en aquellos sectores menos regulados -como la construcción, la agricultura intensiva, las manufacturas de bajo valor añadido, la restauración, el turismo y el ocio, y el servicio doméstico y de cuidado a las personas- y en aquellos puestos de trabajo más precarios en dichos sectores. Sin embargo, y precisamente por dicha precariedad, hay autores que sostienen que los inmigrantes (y especialmente los más recientes) pueden ser capaces de ajustarse 
más rápido y mejor que los trabajadores nativos a las cambiantes condiciones del mercado de trabajo debido a la crisis, puesto que pueden estar más dispuestos a adaptarse a trabajos más precarios y a cambiar de residencia por cuestiones laborales (Papademetriou y Terrazas, 2009).

Según Fielding (2010), en la actual fase del capitalismo posfordista -calificado por algunos como capitalismo de 'casino'- esto sería especialmente cierto en países con una economía y un mercado de trabajo muy dualizados (con sectores de alta productividad y otros de baja productividad) como los países de Asia oriental y del sur de Europa. Estos países se habían convertido, en la fase precedente de crecimiento económico, en grandes receptores de inmigrantes extranjeros debido a un 'nuevo modelo inmigratorio' (King et al., 1997) que los requiere para cubrir los puestos de trabajo con salarios más bajos y condiciones más inestables. Las crecientes diferencias en el tipo de empleos que ocupan los trabajadores autóctonos y los inmigrantes jugarían a favor de estos últimos, según Fielding, en tiempos de recesión: dado que la mayoría de los trabajadores migrantes son 'gap fillers' -es decir, hacen los trabajos que los locales no pueden, o ya no quieren hacer (Abella y Ducanes, 2009)-, cuando sobreviene la crisis y los puestos de trabajo escasean y se precarizan, son los trabajadores autóctonos los más perjudicados. Incluso las empresas -que se han convertido en altamente dependientes de la mano de obra extranjera (Awad, 2009)- han mostrado en algunos países su oposición a las políticas de retorno forzado de los inmigrantes (Castles, 2011). Fielding (2010) opina, con otros autores (Castles, 2011; Ghosh, 2009; Dobson et al., 2009) que este argumento va en contra de la ampliamente aceptada «teoría del amortiguador» (buffer theory) según la cual los migrantes extranjeros servirían para proporcionar mano de obra en los países de acogida en épocas de expansión y para amortiguar el impacto de la crisis en los mercados de trabajo de dichos países al ser los primeros en ser despedidos y en regresar a casa cuando se da una contracción de la economía, liberando puestos de trabajo para los autóctonos. Esta teoría de que el peso de los ajustes de la crisis recae sobre los trabajadores migrantes podía ser cierta en la anterior economía fordista, según Fielding (2010), pero parece ser menos válida en el contexto del actual capitalismo neoliberal.

En este sentido, Martin (2009) señala que esta crisis parece ser diferente a las anteriores, a lo que Castles (2009 y 2011) añade que también los efectos a largo plazo podrían ser diferentes. Para comprenderlos, cree que es útil observar los precedentes históricos: a) La Gran Depresión de los años 30 produjo una disminución masiva de las migraciones laborales internacionales y el regreso (algunas veces obligatorio) de muchos migrantes de países como Estados Unidos y Francia. Sin embargo, esta caída también fue causada, en parte, por las políticas restrictivas de las migraciones adoptadas durante y después de la I Guerra Mundial. b) La recesión que siguió a la Crisis del Petróleo de 1973 tuvo enormes consecuencias para las migraciones, pero casi nadie las pudo prever. En Europa la migración de guestworkers finalizó, pero el asentamiento permanente de los migrantes y las políticas de reagrupación familiar crearon nuevas minorías étnicas en los países de destino. Por otro lado, los altos precios del petróleo atrajeron muchos migrantes extranjeros, a los que los países europeos cerraban las puertas, a los países del Golfo Pérsico. Finalmente, las grandes multinacionales desarrollaron estrategias de exportación de capital y una «nueva división internacional del trabajo» que condujo a la emergencia de nuevos centros industriales, particularmente en Asia y Latinoamérica, y, con el tiempo, a nuevos flujos migratorios por causas laborales. Y c) la crisis financiera asiática de los años 1997-99 tuvo efectos mucho más modestos. Algunos 
gobiernos promulgaron políticas de preferencia de los trabajadores nacionales y buscaron expulsar a los migrantes, particularmente los indocumentados. Sin embargo, las patronales rápidamente descubrieron que los nativos no querían realizar «trabajos de inmigrantes», incluso en época de recesión, y pidieron anular dichas políticas. La interrupción del crecimiento económico asiático fue sin embargo de corta duración y en 1999 la migración internacional empezó a crecer de nuevo, alcanzando nuevas cotas en los años posteriores.

De todas formas, Martin (2009) sostenía hace cuatro años que si la recesión continuara unos años más, no sólo muchos migrantes acabarían volviendo, sino que el flujo de llegada se reduciría significativamente porque los que permanecen recomendarían a los potenciales migrantes que, ante la falta de trabajo, no se movieran de su país. Y esto es lo que, según los últimos datos publicados por el INE (2013), parece que finalmente está sucediendo en España.

La principal lección que se puede aprender de estos ejemplos es que los efectos de las crisis económicas sobre las migraciones son, en cualquier caso, complejos y difíciles de predecir. Además, los migrantes no son unos meros actores económicos que se mueven siempre en busca de la maximización de sus ingresos; son personas que echan raíces y que crean relaciones en los países de acogida. Durante las recesiones, las razones para migrar en busca de trabajo pueden ser incluso más importantes que antes.

Incluso más complejos parecen ser los efectos de la crisis económica global sobre las migraciones no motivadas por criterios laborales, aunque no parece haberse dado un declive generalizado ni en el caso de la reagrupación familiar ni entre los demandantes de asilo. Sin embargo, estas tendencias no se pueden confirmar a nivel internacional porque los datos disponibles son parciales y desiguales. Otros efectos no demográficos derivados de la crisis global serían la reducción de las remesas, lo que podría conducir a más privaciones en las comunidades de los países de origen dependientes de ellas (Ratha et al., 2010), y la creciente hostilidad hacia los migrantes en los países de acogida, con conflictos puntuales así como el auge de partidos xenófobos.

En suma, aunque se trata de una recesión global, sus consecuencias no son homogéneas, variando mucho entre cada país de origen y de destino y entre las diferentes regiones, dependiendo de los diferentes sectores de actividad en los que trabajan los inmigrantes y de las características sociodemográficas (sexo, edad, nacionalidad, nivel de educación...) de éstos. De ahí la importancia, para analizar el impacto que la actual crisis ha tenido en ellos, de estudiar tanto los stocks de migrantes extranjeros como sus flujos migratorios internos en función de las citadas características sociodemográficas.

\section{II.2. La movilidad interna de los extranjeros y su estudio en España}

Los estudios sobre migración interna de extranjeros o minorías étnicas cuentan con un largo arraigo en países con tradición migratoria, y la mayoría de ellos apuntan a la existencia de mayores tasas de movilidad, ya sea por las características demográficas propias de los grupos en cuestión (más jóvenes, en promedio, que los autóctonos, pero también con estructuras familiares diferentes), como por su reciente llegada al país, hecho que significa que no hayan acabado de estabilizar su domicilio de residencia (Trovato, 1988; Bélanger, 1993; Newbold, 1996; Rogers y Henning, 1999; Zorlu y Latten, 2009). Además, el haber realizado ya una migración previa es un factor que facilita un desplazamiento posterior. Geográficamente, estos 
grupos presentan unas pautas de migración que difieren de las registradas por la población autóctona (Frey, 1996; Kempen y Weesep, 1998; Musterd, 2005), ya que, entre los motivos del cambio de residencia, adquiere mayor peso la actividad laboral. Al mismo tiempo, debe considerarse la existencia de zonas específicas que actúan como lugares de entrada iniciales al país, ya sea desde un punto de vista meramente geográfico (Madrid, para los latinoamericanos, por ejemplo) como en relación a ciertos sectores de la actividad laboral (la agricultura o el servicio doméstico, por ejemplo, con una localización territorial divergente), zonas que después actúan como polos de emisión de migrantes extranjeros hacia otras áreas geográficas (Pumares, 2003).

El estudio de la movilidad interna de los extranjeros aporta datos relevantes para entender los determinantes del proceso migratorio (Reher y Silvestre, 2009), pero también contribuye a comprender el proceso de integración de los inmigrantes en el país de llegada así como sus pautas residenciales, o la existencia y evolución de la concentración y la segregación residencial (Sabater et al. 2012). Además, ayuda a entender el impacto territorial de la inmigración, con la existencia de redes migratorias e itinerarios migratorios dentro del país, y son fundamentales en la evolución de los stocks de población de diversos grupos nacionales (Finney y Simpson, 2009) y en diferentes ámbitos geográficos, sean éstos urbanos (Gil-Alonso et al., 2013) o rurales (Bayona y Gil-Alonso, 2013), por su peso en el crecimiento de la población.

Los primeros trabajos sobre las pautas de migración interna de los extranjeros en España se remontan más de diez años atrás. Domingo et al. (2002), en un estudio sobre los jóvenes extranjeros, apuntan la emergencia del fenómeno, mientras que Recaño (2002) realiza el primer análisis pormenorizado de las características de la migración interna de los extranjeros en España. A medida que crecía la importancia de este fenómenos también lo hacía el número de trabajos dedicados a él -por ejemplo, García-Coll (2005 y 2009), Recaño y Domingo (2006), Pumares et al. (2006) y Domingo y Recaño (2007)- así como su variedad temática. Estudios recientes incluso han abordado los determinantes individuales de tales migraciones (Recaño y De Miguel, 2012).

Territorialmente, además del litoral mediterráneo, es en las grandes áreas metropolitanas, especialmente las de Barcelona y Madrid, donde la movilidad interna ha desarrollado un papel más relevante debido a la participación de los extranjeros en los procesos de desconcentración desde el centro metropolitano hacia sus periferias. Así lo afirman los estudios de Bayona y López-Gay (2011) o de Bayona y Gil-Alonso (2012) para la Región Metropolitana de Barcelona, o de Pozo y García (2009) para la Comunidad de Madrid. Pujadas et al. (2012) añaden los casos de Valencia y Sevilla, donde se observan pautas similares de crecimiento migratorio interior. Por otro lado, también algunos trabajos focalizan su atención en la movilidad de grupos de nacionalidades específicos, como los rumanos (Viruela, 2008), latinoamericanos (Gil-Alonso et al. 2012) o marroquíes (Pumares, 2005; Domingo y Bayona, 2007 o Capote, 2012).

En los últimos años, la explotación de los resultados de la Encuesta Nacional de Inmigrantes (ENI) ha aportado nueva información sobre la importancia de los flujos de migración interna de los extranjeros en España. Reher y Silvestre (2011), por ejemplo, han estimado que uno de cada tres migrantes foráneos habría efectuado -en noviembre de 2007- una migración interna en España.

Finalmente, respecto al análisis de los patrones geográficos que presentan estas migraciones internas, Sabater et al. (2012) han estudiado la relación entre la migración interna y la concentración residencial de la población extranjera, mostrando que, en el caso de los grupos 
nacionales mayoritarios, la migración interna habría ayudado al proceso de dispersión en el territorio. Esta desconcentración desde las áreas de primera inserción también es observable a escala inframunicipal, como lo indica el análisis de la movilidad interna de los extranjeros entre barrios de la ciudad de Barcelona (Bayona, 2011), con un centro de la ciudad que reparte extranjeros al resto de la urbe a partir de los cambios de municipio internos.

\section{II.3. El impacto de la crisis sobre las migraciones internas en España}

Menor atención se ha prestado al impacto de la crisis económica sobre las migraciones internas en nuestro país y, particularmente, sobre las de los ciudadanos extranjeros. Respecto a las primeras, Recaño y Cabré (2003) ya identificaron, con anterioridad a la actual crisis, dos efectos de los ciclos económicos regresivos sobre las migraciones internas: una disminución de la intensidad de los flujos interregionales -en línea a lo señalado por Courgeau (1985) - y la aparición de roles distintos de las diferentes Comunidades Autónomas en función del ciclo económico. El impacto de la crisis, especialmente sobre ciertos sectores económicos que atraen mano de obra inmigrante, provocaría una menor atracción de algunos territorios e incluso sería causa de expulsión, tanto del país como de determinadas regiones. Además constataban cómo las crisis afectaban más a ciertos grupos de edad (jóvenes en edades activas) que a otros (mayores, o migrantes de retorno).

Finalmente, los escasos estudios que se han centrado en las pautas de migración interna de los extranjeros en España son, como ya hemos visto, anteriores al inicio de la crisis o no disponían aún de datos que permitían analizar su impacto con suficiente profundidad cronológica (Viruela, 2010; Marcu y Gómez, 2010). De aquí el interés de la presente aportación, que estudia este proceso en el contexto de la evolución experimentada en los últimos años gracias a la disponibilidad de datos actualizados -para 2011 en el momento de realizar esta investigación- procedentes del Padrón continuo y de la Estadística de Variaciones Residenciales.

\section{FUENTES ESTADÍSTICAS}

Este trabajo se ha realizado con información procedente, en su mayoría, de dos fuentes estadísticas elaboradas y publicadas por el Instituto Nacional de Estadística (INE): el Padrón continuo de población, que recoge desde 1996 los stocks de población según su nacionalidad, sexo y edad; y la Estadística de Variaciones Residenciales (EVR) que publica las altas y bajas de los padrones municipales (flujos) producidas por cambios de residencia (inmigración y emigración).

El Padrón continuo es la estadística que resulta de recoger, chequear y depurar los datos de los stocks de población que se registran en los padrones municipales. Desde 1998 ofrece la información con fecha a 1 de enero, dando la cifra oficial de población de cada municipio español y, en consecuencia, la del conjunto del país. En su explotación estadística se proporciona la información de la nacionalidad, país de nacimiento y características demográficas básicas de la población empadronada. Dado que, de acuerdo con la Ley de Bases de Régimen Local, todas las personas residentes en un municipio español tienen el derecho y el deber de empadronarse, se considera que sus cifras, sin ser exactas, proporcionan una buena aproxi- 
mación al número de extranjeros. Y ello a pesar de las dudas surgidas en los últimos años en torno a la utilización política del padrón, que puede haber causado la invisibilización -si quiera parcial- de algunos colectivos extranjeros, con un impacto territorial desigual en función de las políticas restrictivas de cada municipio (Domingo y Sabater, 2010).

Por su parte, la Estadística de Variaciones Residenciales (EVR) recoge los flujos entre municipios españoles, o entre uno de ellos y el exterior, a partir de las altas y bajas en el Padrón de población. La elabora anualmente el INE gracias a la explotación de los padrones municipales y se considera de buena calidad en lo que concierne a las migraciones entre municipios españoles (Recaño, 2002; Martí y Ródenas, 2006). Más dudas generan las cifras de migraciones procedentes del exterior y, sobre todo, las que recogen los flujos de salida hacia otros países, pues muchos emigrantes no se dan de baja del municipio de partida. Es una estadística que recoge movimientos y no personas, incluyendo por lo tanto reemigraciones (Martí y Ródenas, 2012), y con la posibilidad, como registro administrativo, de contener falsas migraciones (por ventajas del empadronamiento diferencial) o de que el registro se produzca con un desfase temporal con el fenómeno. Para intentar solucionar estos problemas, el INE acaba de publicar una nueva serie de datos, la denominada Estadística de Migraciones, que tiene como finalidad estimar las migraciones internas y externas tras someter a las EVR a una serie de correcciones y que está ligada a otra operación estadística también novedosa, las Cifras de Población, que cuantifica la población residente en España y en sus diferentes niveles administrativos (INE, 2013). Sin embargo, dicha Estadística de Migraciones no contempla, por un lado, las migraciones intraprovinciales, y por el otro tan sólo se encuentra disponible a partir del año 2008, año donde los efectos de la crisis económica ya se dejaban notar en la evolución de los flujos migratorios, razón por la cual se ha preferido seguir utilizando las Estadísticas de Variaciones Residenciales.

\section{UN BREVE APUNTE A LOS EXTRANJEROS RESIDENTES EN ESPAÑA Y A SUS FLUJOS MIGRATORIOS CON EL EXTERIOR.}

\section{IV.1. Las entradas de extranjeros a España desde el exterior}

El año 2007 fue el que registró mayores entradas migratorias de extranjeros en España, cuando más de 920 mil extranjeros se dieron de alta en los padrones municipales. Esa cifra, la más elevada en el entorno europeo, venía creciendo progresivamente desde finales de la década de los noventa (junto con la mejora del registro), y en 2007 tuvo a los europeos como principales protagonistas, con 420 mil entradas, un $45 \%$ de todas las registradas (ver figura 1). El año 2008 representa el primer punto de inflexión, al entrar 690 mil personas, con un descenso muy importante de los europeos (220 mil entradas, casi la mitad del año anterior), y también, aunque menor, de los americanos, mientras africanos y asiáticos seguían aumentando sus entradas. El efecto de la crisis se deja notar, en primer lugar, en los flujos de mayor proximidad, y sobre todo entre los rumanos, que descienden en un año de las 197 mil entradas a las 71 mil. En 2009, las entradas siguen disminuyendo hasta las 469 mil, después de un descenso importante entre africanos y americanos, para una posterior estabilización en los dos años posteriores, para situarse en las 416 mil de 2011. Al mismo tiempo que descienden las altas, empiezan a aumentar las salidas de extranjeros, aunque su registro siempre es 
problemático y no siempre se produce al mismo tiempo que la baja es efectiva, quizás con ligeros retrasos. De esta forma, en 2011 hasta 317 mil extranjeros salen de España, lo que aún, según la EVR, daría un ligero saldo positivo de prácticamente 100 mil movimientos.

Figura 1

ALTAS Y BAJAS DE EXTRANJEROS EN ESPAÑA CON ORIGEN O DESTINO AL EXTRANJERO, POR AGRUPACIÓN CONTINENTAL, 2001-2011

Altas

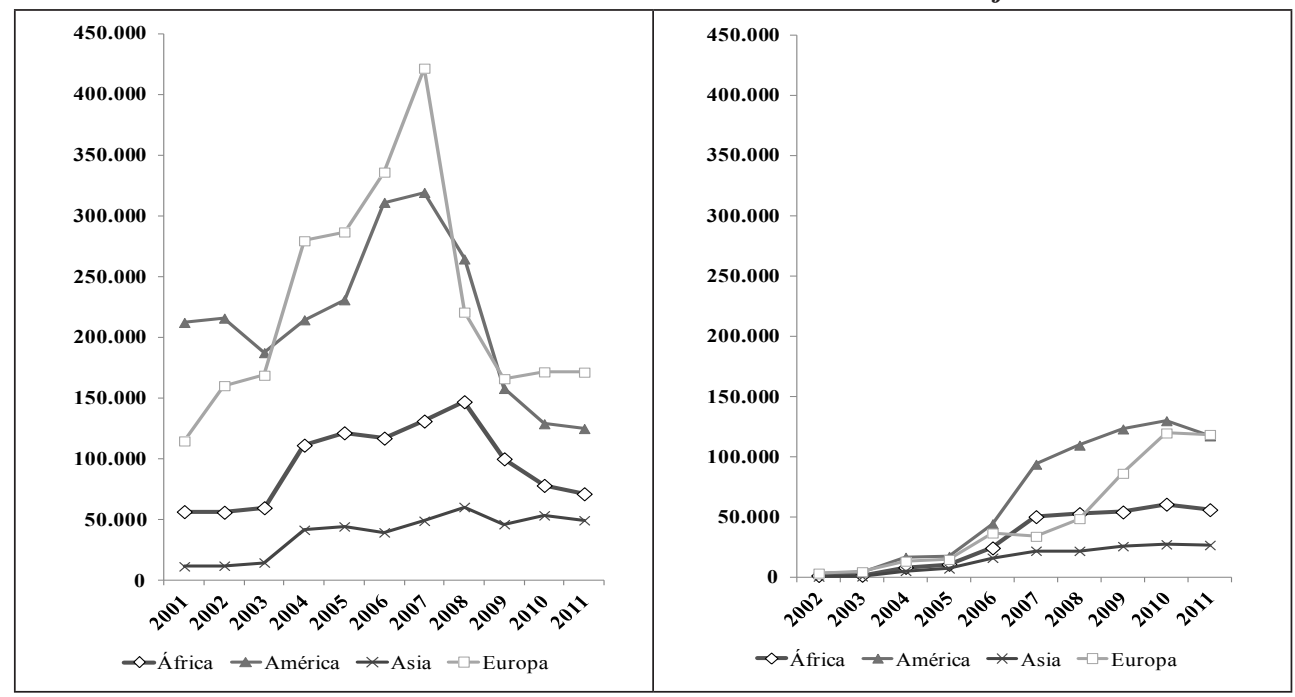

Fuente: Estadística de Variaciones Residenciales, 2001-2011, con datos del INE.

Una estimación a los flujos de salida los aporta la estadística de flujos asociada a las Estimaciones de Población Actual (EPOBAS) que publica el INE, donde las bajas para el año 2011 ascienden a 445 mil (por 415 mil altas, cifra ésta prácticamente coincidente con la EVR), lo que reportaría ya un saldo negativo, por primera vez en la historia reciente, de la dinámica migratoria internacional en aproximadamente treinta mil personas (de 34 mil entre africanos, 7 mil entre los asiáticos y 20 mil para los americanos, por un saldo positivo de europeos).

\section{IV.2. La evolución reciente de los stocks de población extranjera en España}

Con los datos del último año disponible, a 1 de enero de 2012 en España se encontraban empadronados 5.736.258 residentes extranjeros, que representaban el 12,1\% de la población española, cifra que por primera vez desde la implantación del Padrón continuo experimenta un ligero retroceso, después del máximo de 2011 de 5.751 .487 personas, o en relación con el total del 12,2\% que representaban en 2010. El estancamiento del número de extranjeros refleja el cambio de dinámica migratoria y los efectos de la crisis económica, mientras que el ligero descenso en los datos se debe, en buena parte, al crecimiento de las nacionalizaciones y a la menor entrada de nuevos flujos migratorios. Por otra parte, los primeros resultados del Censo 
de 2011, con fecha de referencia a 1 de noviembre, disminuyen la población extranjera presente en España en aproximadamente medio millón (en relación con el Padrón continuo), descenso que se produce de forma más acusada entre aquellas nacionalidades pertenecientes a la antigua UE15. El proceso de depuración de las cifras padronales, que son la base del Censo de 2011, arroja para algunas nacionalidades, según la nota metodológica que acompaña a los resultados, serias dudas sobre su presencia efectiva en España. De esta forma, los ciudadanos británicos y alemanes conocen una reducción del 20,2\% y $21,8 \%$ de sus efectivos padronales, por un $17,7 \%$ de los franceses. Con alguna excepción (es el caso de los rusos), la mayoría de nacionalidades europeas conocen decrecimientos alrededor del 10\% de sus efectivos del Padrón.

Volviendo al Padrón, en la composición por nacionalidades en el año 2012 el 46,9\% de los extranjeros presentes son de nacionalidad europea, por un $27,4 \%$ de americanos, un $22,6 \%$ de africanos y sólo un $6 \%$ de asiáticos. Entre las principales nacionalidades destacan los rumanos (897 mil), marroquíes (788 mil), británicos (397 mil) o ecuatorianos (308 mil, aunque residen en España 471 mil nacidos en el Ecuador), mientras los primeros asiáticos son los chinos (177 mil).

La distribución territorial de la población extranjera es muy desigual, con un litoral mediterráneo, archipiélagos y Madrid donde se concentra buena parte de la población extranjera, con provincias como Alicante, con un 24,3\% de extranjeros, o Almería, Baleares o Girona por encima del 20\%, mientras que los mínimos se encuentran en el norte de España (A Coruña, 3,5\%) y en sur (Córdoba, 3,2\%). Las provincias más urbanas, turísticas litorales y de agricultura intensiva son las que concentran la mayor parte de extranjeros empadronados. En la evolución más reciente, y especialmente desde el año 2008, se puede observar cómo varían muy poco los porcentajes de residentes extranjeros, y que incluso se observan algunos primeros descensos, sea el caso de las provincias de Madrid y Valencia, mientras que los mayores crecimientos se producen en el litoral cantábrico, Extremadura y algunas provincias andaluzas, a pesar de que siguen moviéndose en valores reducidos. Como ejemplo, Álava pasa de un 7,4\% a un $9,4 \%$ entre 2008 y 2012; Soria del $8,9 \%$ al $10,5 \%$ o Sevilla, del 3,3\% al 4,2\%, donde en un contexto de estabilización algunas provincias incrementan de forma significativa los extranjeros empadronados (es el caso de Álava, Sevilla o Jaén, con crecimientos del 32\%). Por nacionalidades existen pautas desiguales, con una concentración de europeos en las zonas litorales o insulares turísticas y Madrid; una sobrerrepresentación de americanos en las ciudades de las áreas más pobladas, de africanos en Cataluña y las zonas agrícolas de Andalucía y Murcia; o de asiáticos en Barcelona.

\section{LA EVOLUCIÓN DE LA MOVILIDAD INTERNA: DEL MÁXIMO DE 2007 AL EFECTO DE LA CRISIS ECONÓMICA}

\section{V.1. Características de las migraciones internas protagonizadas por extranjeros}

El año 2007 fue, hasta ahora, el momento de mayores flujos migratorios internos en España, cuando las EVR registran un total de 1.795.353 movimientos internos. Más de un millón de ellos se produjeron sin superar un límite provincial (1.050.637, el 58,5\% de toda la movilidad), y en 744.716 casos se traspasaron los límites provinciales. Desde entonces, la movilidad interna decrece levemente, y en 2011 se observan 1.650.298 movimientos, el 59,3\% dentro de una 
misma provincia. El comportamiento de españoles y extranjeros presenta alguna divergencia. Por un lado, la máxima movilidad de españoles se produjo en 2006, y desde entonces el descenso fue poco pronunciado, inferior al $5 \%$ total (figura 2, izquierda). Entre los extranjeros, en cambio, el máximo se produjo más tarde, en 2007, con 535.193 desplazamientos, que bajan hasta los 439.992 del último año, con un descenso del 17,7\% (figura 2, centro). Dos terceras partes del descenso global desde 2007 deben atribuirse a la menor movilidad de los extranjeros. En cuanto a la tipología del desplazamiento, entre los extranjeros tienen mayor peso el desplazamiento interprovincial, que representa alrededor del $45 \%$ de sus desplazamientos, cuando entre los españoles se sitúa por debajo del $40 \%$. De esta relación surge un mayor peso de los extranjeros en los desplazamientos entre provincias, con un máximo en 2007, cuando uno de cada tres movimientos interprovinciales lo realizaba un extranjero (figura 2, derecha).

Figura 2

EVOLUCIÓN DE LA MOVILIDAD INTERNA EN ESPAÑA SEGÚN NACIONALIDAD Y RELACIÓN ENTRE ORIGEN Y DESTINO, 1998-2011

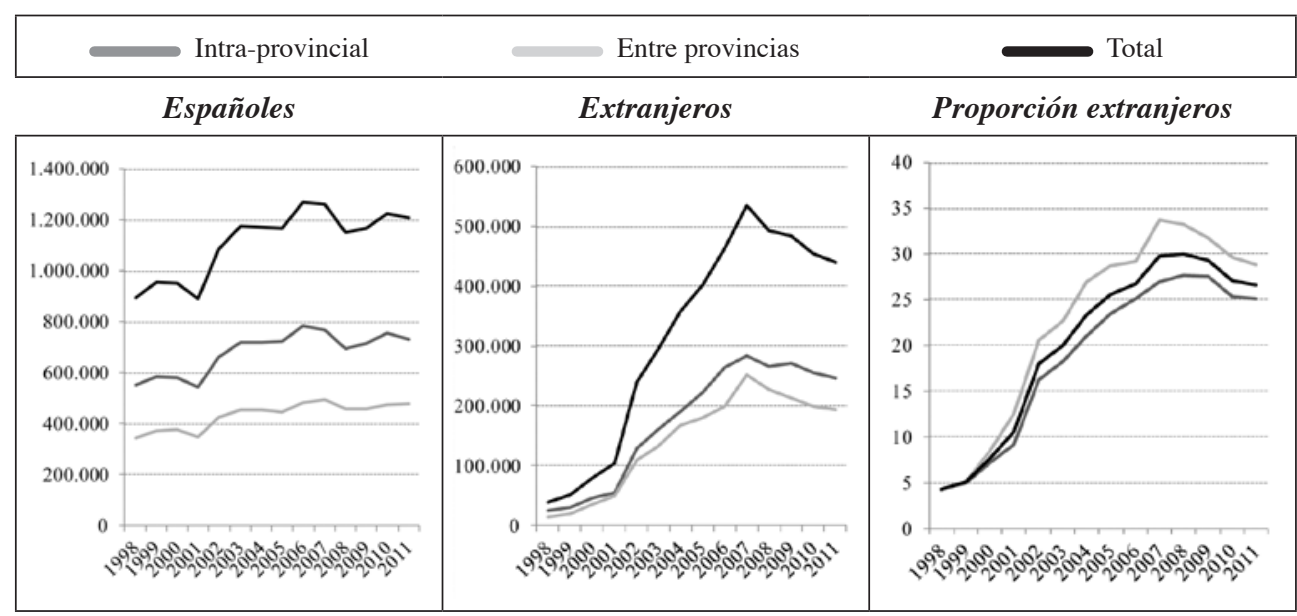

Fuente: Estadística de Variaciones Residenciales (INE), 1998-2011.

La sobrerrepresentación de los extranjeros en la movilidad total, muy por encima de su peso en el conjunto de la población, tiene su origen en unas tasas de migración interna de mayor intensidad que la de los españoles, como se observa en la figura 3. Si los españoles presentan una tasa de 29,2 migraciones internas por cada mil habitantes, la tasa de los extranjeros alcanza el 76,6\%o, lo que produce una tasa global del 34,9\%o. Son tasas descendentes desde sus máximos respectivos en 2006 del 31,2\%o y en 2007 del 109,4\%o, con un descenso más notable de la intensidad de la migración interna entre los extranjeros (figura 3). Por agrupaciones continentales, las tasas de algunos grupos extranjeros son mucho más altas, sea el caso de los asiáticos (138\% en 2011, con un máximo de 189\%o en 2007), africanos (107\%o, con $143 \%$ en 2007), e americanos (104\%o, con 122\%o en 2007), otras están más próximas a los españoles, como los europeos de la antigua UE15 (32,1\%o, con un máximo en 2004 de 54,3\%o) o del resto de Europa (56,4\%o con el máximo de 119\%o en 2002). 
Figura 3

TASAS DE MIGRACIÓN INTERNA (X1000) POR GRUPOS CONTINENTALES

DE NACIONALIDAD. ESPAÑA, 1998-2011
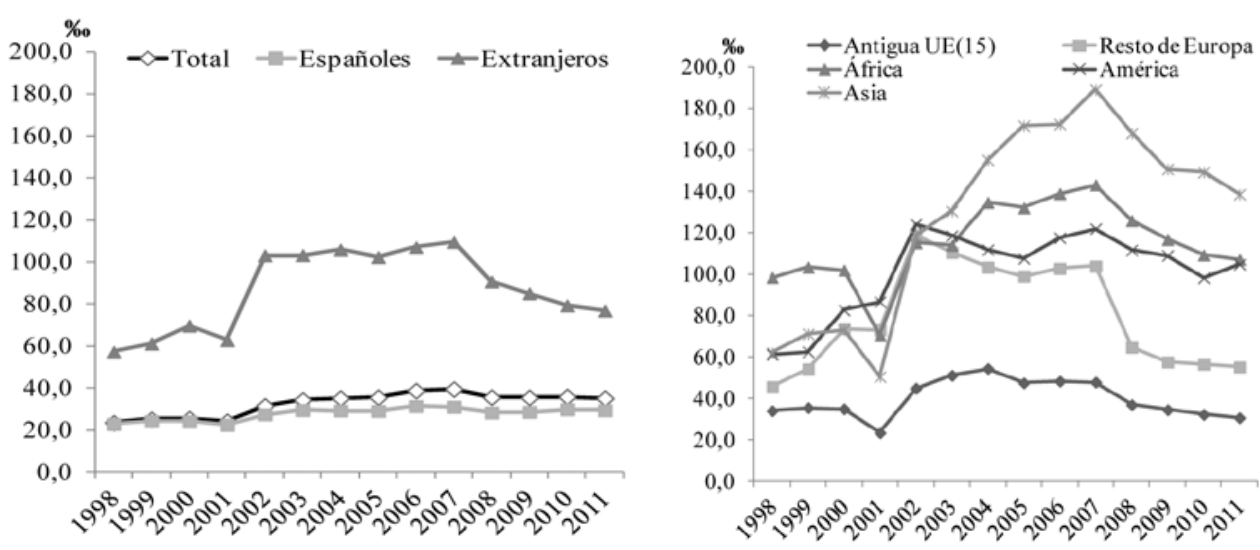

Fuente: Estadística de Variaciones Residenciales (INE), 1998-2011.

Es evidente que estas altas tasas de movilidad interna son debidas, en parte, a su estructura por edades, mucho más rejuvenecida que la de los españoles y con una concentración en las edades de mayor movilidad. Aún así, las tasas específicas de migración interna por sexo y edades confirman la mayor movilidad de los extranjeros en la mayoría de edades (a excepción de aquellas más avanzadas), especialmente durante todas las edades activas, y ello pese a la disminución que tales tasas han experimentado entre 2007 y 2011 debido a la crisis (figura 4).

Figura 4

TASAS DE MIGRACIÓN INTERNA (X1000) POR NACIONALIDAD, SEXO Y EDAD, ESPAÑA, 2007 Y 2011

2007

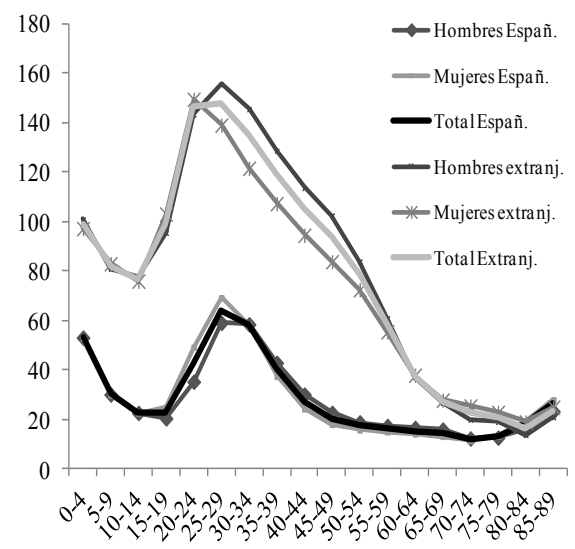

2011

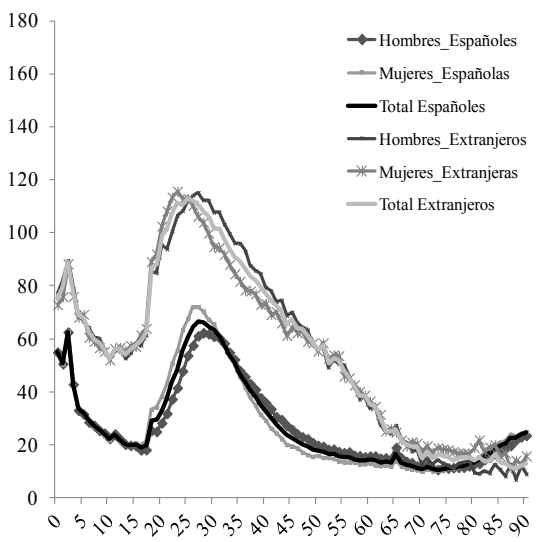

Fuente: Estadística de Variaciones Residenciales (INE), 2011 y Padrón continuo, 2011 y 2012. 
Europeos

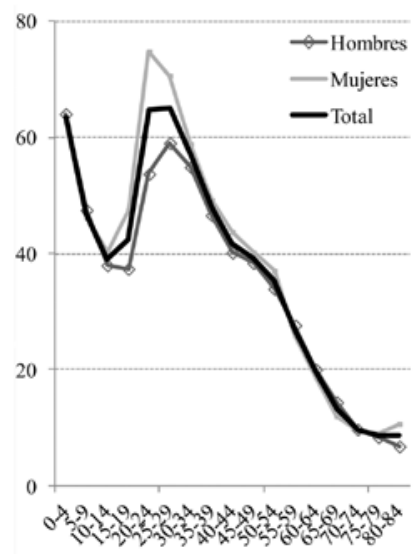

Americanos

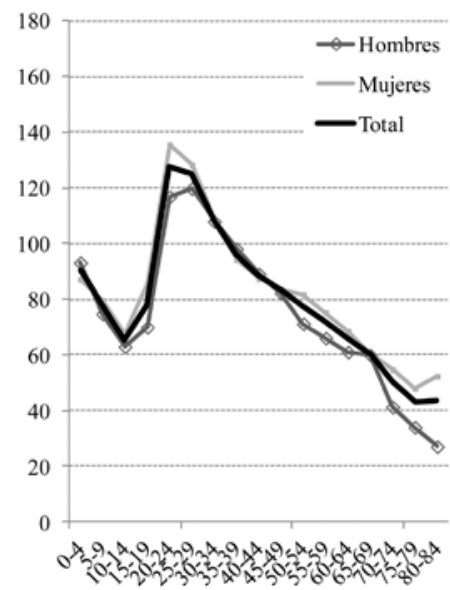

Africanos

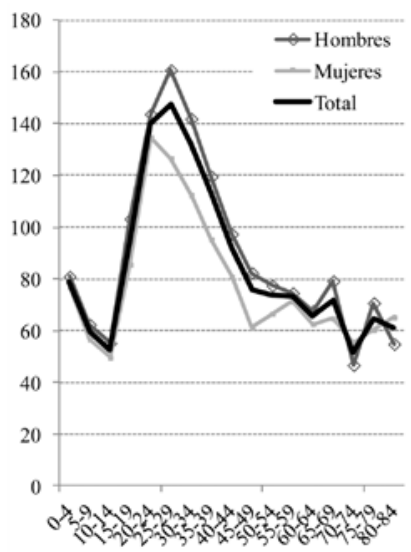

Asiáticos

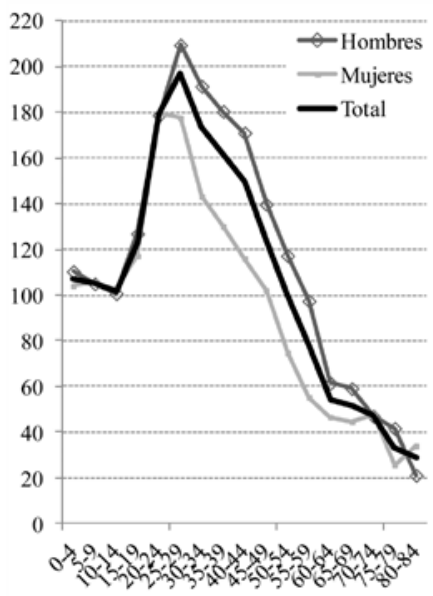

Fuente: Estadística de Variaciones Residenciales (INE), 2011 y Padrón continuo de la población, 2011 y 2012.

Por grupos continentales, las pautas de migración interna por sexo y edad de los europeos son semejantes en su intensidad a la de los españoles, con mayores tasas de migración entre las mujeres (figura 5). Los tres grupos restantes, en cambio, muestran tasas mucho mayores. Americanos y africanos se asemejan en la intensidad, aunque para los segundos las tasas de los hombres son mayores, mientras que entre los americanos lo son ligeramente las de las mujeres. Las tasas más elevadas se producen entre los asiáticos, que al mismo tiempo muestran las mayores diferencias entre hombres y mujeres. 


\section{V.2. El impacto de la crisis: la situación de las migraciones internas en el año 2011}

En 2011 de los más de 1,65 millones de movimientos migratorios interiores registrados en España, casi 440 mil fueron realizados por un residente extranjero, lo que significa un $26,7 \%$, porcentaje que aumenta ligeramente si en esta migración se traspasa un límite provincial $(28,9 \%)$, debido a que 44 de cada 100 migraciones internas protagonizadas por extranjeros se realizaron entre municipios de distintas provincias. En este sentido, los extranjeros europeos y los americanos se asemejarían más a las pautas de desplazamiento de los españoles, en cuanto el peso de su movilidad interprovincial es similar (justo por encima del $39 \%)$, mientras que para los asiáticos $(52,6 \%)$ y los africanos $(51,6 \%)$ es más sencillo traspasar un límite provincial (tabla 1). Del conjunto de la movilidad de la población extranjera del año 2011, un 35,6\% fue realizada por americanos, un 26,4\% por europeos, un $26 \%$ por africanos y el $11,9 \%$ restante por asiáticos. Si se considera la movilidad interprovincial, la importancia de africanos y asiáticos es mayor (30,4\% y 14,2\%, respectivamente).

Tabla 1 MOVILIDAD INTERNA EN ESPAÑA SEGÚN NACIONALIDAD Y CAMBIO DE PROVINCIA, 2011

\begin{tabular}{lrrrr} 
& $\begin{array}{r}\text { (1) Inter- } \\
\text { provincial }\end{array}$ & $\begin{array}{r}\text { (2) Intra- } \\
\text { provincial }\end{array}$ & $\begin{array}{r}\text { (3) Movilidad } \\
\text { interna }\end{array}$ & \% (1/3) \\
Españoles & 477.955 & 732.351 & 1.210 .306 & 39,5 \\
Extranjeros & 194.048 & 245.944 & 439.992 & 44,1 \\
$\quad$ América & 61.604 & 95.175 & 156.779 & 39,3 \\
$\quad$ África & 59.037 & 55.441 & 114.478 & 51,6 \\
$\quad$ Europa & 45.829 & 70.457 & 116.286 & 39,4 \\
$\quad$ Asia & 27.464 & 24.758 & 52.222 & 52,6 \\
Total & $\mathbf{6 7 2 . 0 0 3}$ & $\mathbf{9 7 8 . 2 9 5}$ & $\mathbf{1 . 6 5 0 . 2 9 8}$ & $\mathbf{4 0 , 7}$ \\
& & & & \\
Marruecos & 36.858 & 40.446 & 77.304 & 47,7 \\
Rumanía & 20.964 & 27.917 & 48.881 & 42,9 \\
China & 15.968 & 12.122 & 28.090 & 56,8 \\
Colombia & 13.852 & 17.633 & 31.485 & 44,0 \\
Ecuador & 8.758 & 13.518 & 22.276 & 39,3 \\
Pakistan & 6.618 & 6.404 & 13.022 & 50,8 \\
Bolivia & 6.545 & 10.753 & 17.298 & 37,8 \\
Rep. Dominicana & 4.800 & 6.366 & 11.166 & 43,0 \\
Brasil & 4.551 & 7.013 & 11.564 & 39,4 \\
Nigeria & 4.502 & 3.088 & 7.590 & 59,3 \\
\hline
\end{tabular}

Fuente: Estadística de Variaciones Residenciales, 2011, con datos del INE.

En cuanto al perfil presentado por sexo y edad, en valores absolutos destaca una movilidad concentrada en las edades adultas jóvenes, con un arrastre de menores destacado entre los africanos (figura 6). Por sexos, las migraciones masculinas son mayoritarias entre los 
africanos $(67 \%)$ y los asiáticos $(65 \%)$, especialmente en aquellas edades de mayor número de movimientos, mientras que hay más flujos femeninos entre los europeos $(51,2 \%)$ y los americanos $(57,4 \%)$. Es entre algunas nacionalidades asiáticas, como los pakistaníes o los indios, donde la preponderancia del hombre es más clara $(86,1 \%$ y $80,5 \%)$, también entre algunos subsaharianos como senegaleses $(84,7 \%)$ o malienses $(95,8 \%)$. En el lado opuesto, entre los brasileños, hondureños y nicaragüenses los hombres tienen menor representación, y se reducen al $31,6 \%, 23,9 \%$ o $18,9 \%$, respectivamente.

Figura 6

MOVIMIENTOS DE EXTRANJEROS EN ESPAÑA SEGÚN SEXO Y EDAD, 2011
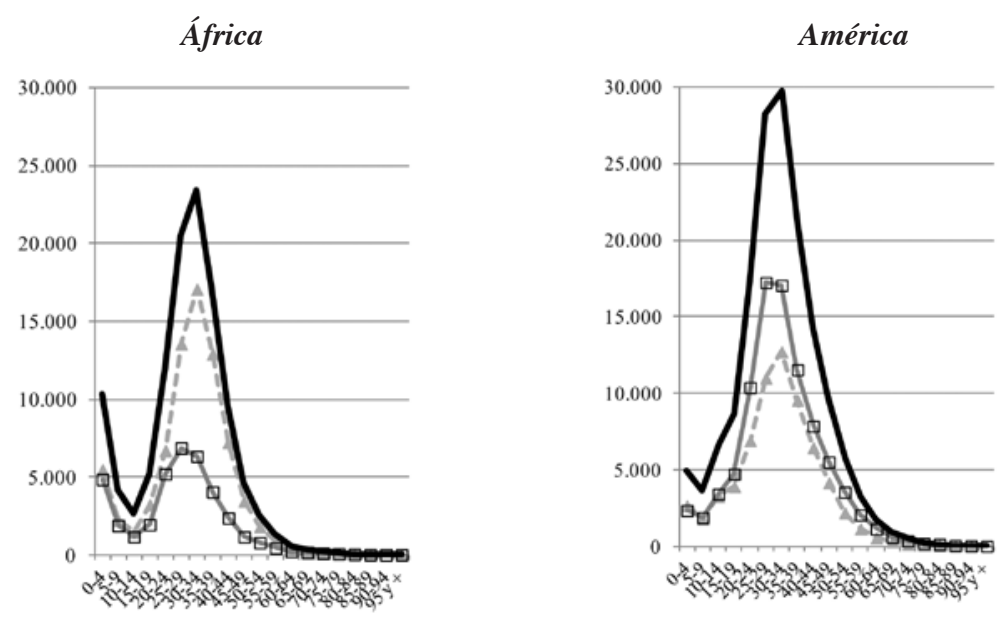

Asia

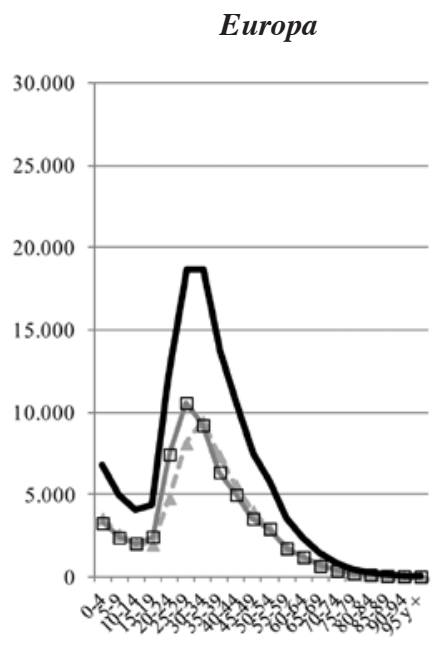

Fuente: Estadística de Variaciones Residenciales, 2011, con datos del INE. 
Finalmente, se ha calculado un indicador de intensidad: el Indicador Sintético de Migración interna $(\mathrm{ISMi})^{2}$, cuyo resultado nos indicaría el número de cambios migratorios internos que se realizarían a lo largo de una vida si se mantuvieran las tasas observadas en el año estudiado (de forma similar al conocido ISF, Índice Sintético de Fecundidad). Los resultados obtenidos nos indican que los españoles, con independencia del sexo, realizarían 2,5 cambios de municipio a lo largo de su vida con las tasas observadas en 2011, valor que para los extranjeros se dobla, con justo 5 movimientos. Éstos, por grupo continental, oscilan entre el mínimo de los europeos (3 para los hombres y 3,3 para las mujeres) y el máximo de los asiáticos $(9,9$ y 8,1$)$, pasando por los valores de africanos $(7,9$ y 6,8) y americanos $(6,5$ y $7,2)$. Con este indicador se observa la alta intensidad de las migraciones internas de algunos colectivos, así como de las diferencias entre sexos en la migración interna.
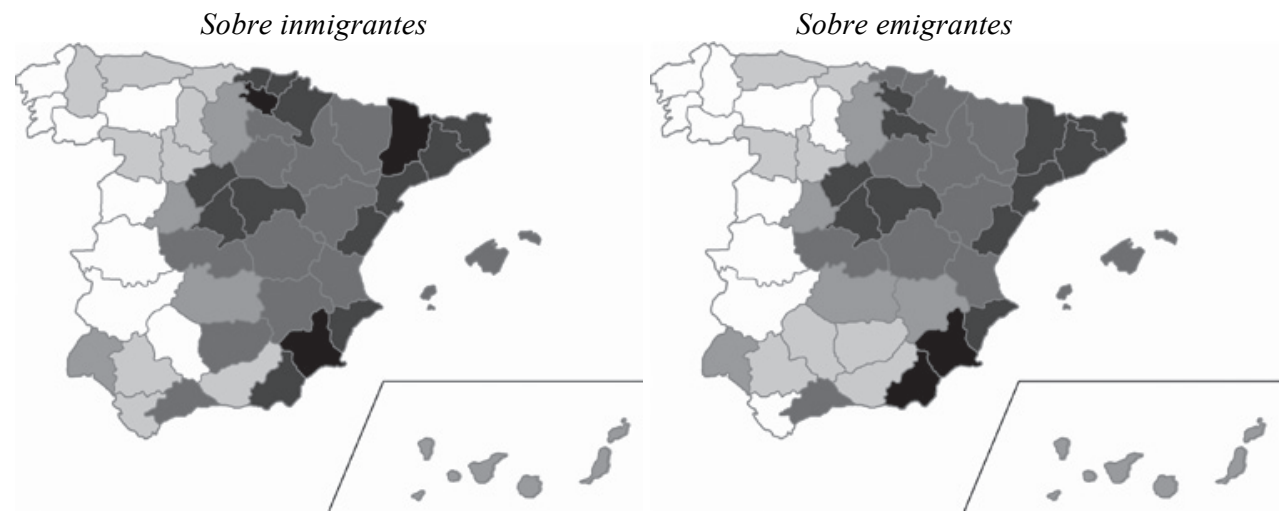

Menos del $15 \%$
Entre el $15 \%$ y el $20 \%$

Entre el $20 \%$ y $25 \%$

Entre el $25 \%$ y el $30 \%$

Entre el $30 \%$ y el $35 \%$

Más del $35 \%$

Fuente: Estadística de Variaciones Residenciales, 2011, con datos del INE

Desde un punto de vista territorial, el peso de los extranjeros en el conjunto de emigrantes internos varía entre el mínimo de Ourense (10,3\%) y el máximo de Almería (37,8\%), mientras que entre los inmigrantes internos el mínimo es del 11,6\% en Cáceres y el máximo del $38,3 \%$ en Álava (figura 7). Si la perspectiva es municipal, encontramos cómo buena parte de los municipios españoles experimentan una participación de los extranjeros en los flujos migratorios internos muy por encima del $26,7 \%$ del conjunto español. En los casos más extremos, en 534 municipios los extranjeros representan como mínimo la mitad de las llega-

2 El Índice Sintético de Migración Interna (ISMi) es un indicador de intensidad, cuyo resultado es el número de migraciones internas en España que realizaría una persona si las pautas de migración interna del periodo observado permaneciesen estables a lo largo de la vida: $I S M i=\frac{\left.\sum m_{\chi} * n\right)}{1000}$, donde $m x$ es la tasa específica de migración
interna y $n$ es la amplitud del intervalo de edad. 
das, y en 391 la mitad de las salidas. Esto se produce especialmente en municipios del centro de España, alrededor de la Comunidad de Madrid, pero también en el litoral mediterráneo (especialmente en Murcia) y en los archipiélagos, a los que se suman algunos municipios del eje del Ebro. Por el contrario, hasta 2.467 municipios españoles no recibieron a ningún extranjero como migrante interno en 2011, y en 2.300 no hubo emigrantes no españoles (figura 8).
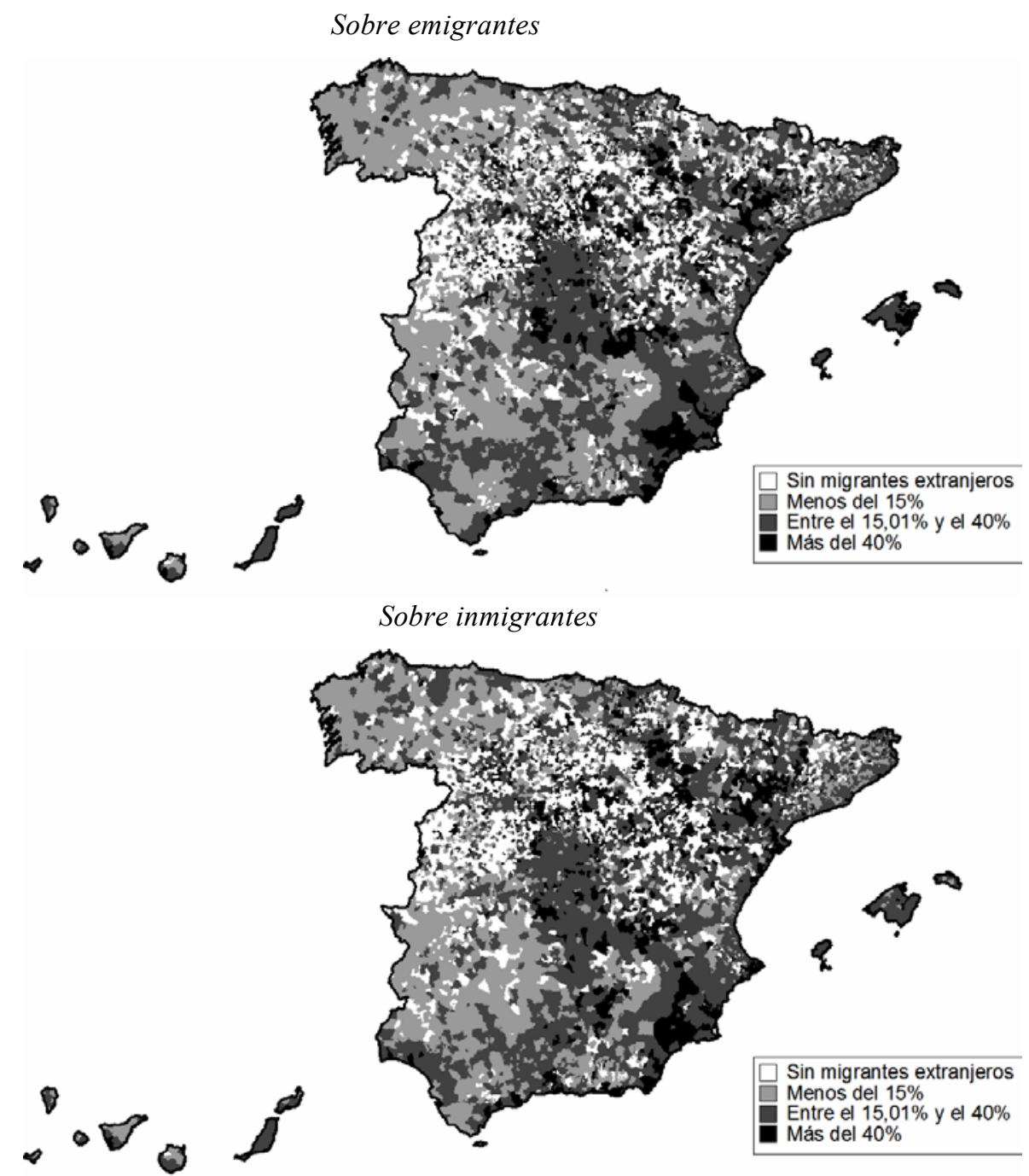

Fuente: Estadística de Variaciones Residenciales, 2011, con datos del INE. 
Además de la amplia dispersión territorial, encontramos cómo en los municipios de mayor peso demográfico la presencia en los flujos internos de los extranjeros está muy por encima de su peso en el conjunto de la ciudad (tabla 2), con porcentajes que superan el $30 \%$ en Madrid y Barcelona (superiores en el segundo caso) y que en algunas ciudades de sus respectivas áreas metropolitanas se sitúan por encima del 50\% (L'Hospitalet de Llobregat), o cerca de dicho porcentaje (Badalona, Móstoles o Fuenlabrada, entre otros). En muchas de las grandes urbes españolas, además, se experimenta un saldo neto negativo de residentes extranjeros, que se distribuyen mayoritariamente por sus respectivas áreas metropolitanas vía movilidad residencial (Pujadas et al. 2012).

Tabla 2

PRESENCIA DE EXTRANJEROS EN LOS FLUJOS MIGRATORIOS INTERNOS DE LOS MUNICIPIOS ESPAÑOLES DE MÁS DE 250 MIL HABITANTES

\begin{tabular}{|c|c|c|c|c|c|c|c|c|c|c|}
\hline \multirow[b]{3}{*}{ Madrid } & \multicolumn{4}{|c|}{ Inmigrantes } & \multicolumn{4}{|c|}{ Emigrantes } & \multirow{2}{*}{\multicolumn{2}{|c|}{$\begin{array}{l}\text { \%resid. S. migrat. } \\
\text { extranj. Extranj. }\end{array}$}} \\
\hline & Españ. & Extranj. & Total & $\%$ extranj. & Españ. & Extranj. & Total & $\%$ extranj. & & \\
\hline & 62.674 & 28.638 & 91.312 & 31,4 & 65.424 & 30.527 & 95.951 & 31,8 & 15,5 & -1.889 \\
\hline Barcelona & 32.755 & 20.205 & 52.960 & 38,2 & 34.147 & 20.436 & 54.583 & 37,4 & 17,5 & -231 \\
\hline Valencia & 16.605 & 8.417 & 25.022 & 33,6 & 18.812 & 8.572 & 27.384 & 31,3 & 13,4 & -155 \\
\hline Sevilla & 11.832 & 2.833 & 14.665 & 19,3 & 14.691 & 2.602 & 17.293 & 15,0 & 5,6 & 231 \\
\hline Zaragoza & 11.173 & 3.614 & 14.787 & 24,4 & 9.143 & 4.426 & 13.569 & 32,6 & 12,9 & -812 \\
\hline Málaga & 9.536 & 3.450 & 12.986 & 26,6 & 11.548 & 3.028 & 14.576 & 20,8 & 8,6 & 422 \\
\hline Murcia & 6.513 & 3.113 & 9.626 & 32,3 & 6.415 & 3.571 & 9.986 & 35,8 & 12,8 & -458 \\
\hline Palma de Mallorca & 10.239 & 4.708 & 14.947 & 31,5 & 10.929 & 4.160 & 15.089 & 27,6 & 20,2 & 548 \\
\hline Palmas G. Canaria & 9.013 & 1.676 & 10.689 & 15,7 & 9.920 & 1.984 & +11.904 & 16,7 & 7,9 & -308 \\
\hline Bilbao & 6.375 & 4.011 & 10.386 & 38,6 & 6.915 & 3.351 & 10.266 & 32,6 & 8,5 & 660 \\
\hline Alacant/Alicante & 6.878 & 3.103 & 9.981 & 31,1 & 7.577 & 2.846 & 10.423 & 27,3 & 14,8 & 257 \\
\hline Córdoba & 4.751 & 709 & 5.460 & 13,0 & 5.078 & 801 & 5.879 & 13,6 & 2,8 & -92 \\
\hline Valladolid & 6.463 & 1.174 & 7.637 & 15,4 & 7.196 & 1.245 & 8.441 & 14,7 & 5,9 & -71 \\
\hline Vigo & 5.739 & 969 & 6.708 & 14,4 & 5.760 & 893 & 6.653 & 13,4 & 5,7 & 76 \\
\hline Gijón & 4.980 & 1.097 & 6.077 & 18,1 & 4.475 & 929 & 5.404 & 17,2 & 5,2 & 168 \\
\hline L'Hospitalet Llobr. & 6.481 & 7.394 & 13.875 & 53,3 & 7.363 & 7.686 & 15.049 & 51,1 & 22,6 & -292 \\
\hline
\end{tabular}

Fuente: Estadística de Variaciones Residenciales, 2011, y Padrón continuo 2012, con datos del INE.

\section{V.3.Las pautas geográficas de migración interna bajo la crisis: diferencias según grupos de nacionalidades}

Una de las hipótesis de partida de este trabajo era la existencia de cambios importantes en las pautas de movilidad interna, ya que la crisis ha modificado enormemente la capacidad de atracción de algunas provincias (por ejemplo, aquellas con mayor importancia de la construcción), al mismo tiempo que puede reforzar la capacidad de retención de otras, ya sean grandes ciudades (donde por su estructura laboral, más diversificada y decantada al sector terciario) o áreas agrícolas, las cuales resisten mejor el primer impacto de la crisis. Para observar esta situación, a continuación se ha cartografiado los flujos migratorios más importantes de los años 2007 y 2011, así como también el saldo migratorio de cada una de las provincias, todo ello a nivel provincial y de continente de nacionalidad (figura 9, $10,11$ y 12$)$. 
En primer lugar, se observa que las migraciones interprovinciales de los europeos sufren entre los años 2007 y 2011 un importante descenso (de una intensidad del 34\%), de 69.456 movimientos a 45.829. Esto se manifiesta de forma geográfica con un descenso de la magnitud de los principales flujos migratorios existentes en 2007, en especial en las provincias valencianas de Alicante y Valencia (figura 9). Destaca también la no aparición de nuevos espacios de asentamiento importantes en 2011, y en cambio disminuyen los flujos entre Madrid y Zaragoza, o entre Madrid o Barcelona con Castellón. Se mantienen, en cambio, los flujos entre Madrid y Guadalajara y Toledo, o de Barcelona con Girona y Tarragona, viéndose menos afectados aquellos flujos interprovinciales con zonas colindantes. Al mismo tiempo, los saldos migratorios resultantes experimentan pequeñas variaciones entre los dos años, la principal de ellas se observa en la provincia de Madrid, que de clara expulsora de migrantes europeos en 2007 pasa, en cambio, a un saldo positivo en 2011. Es, además, la única provincia que experimenta este tipo de situación, al contrario, varias provincias antes

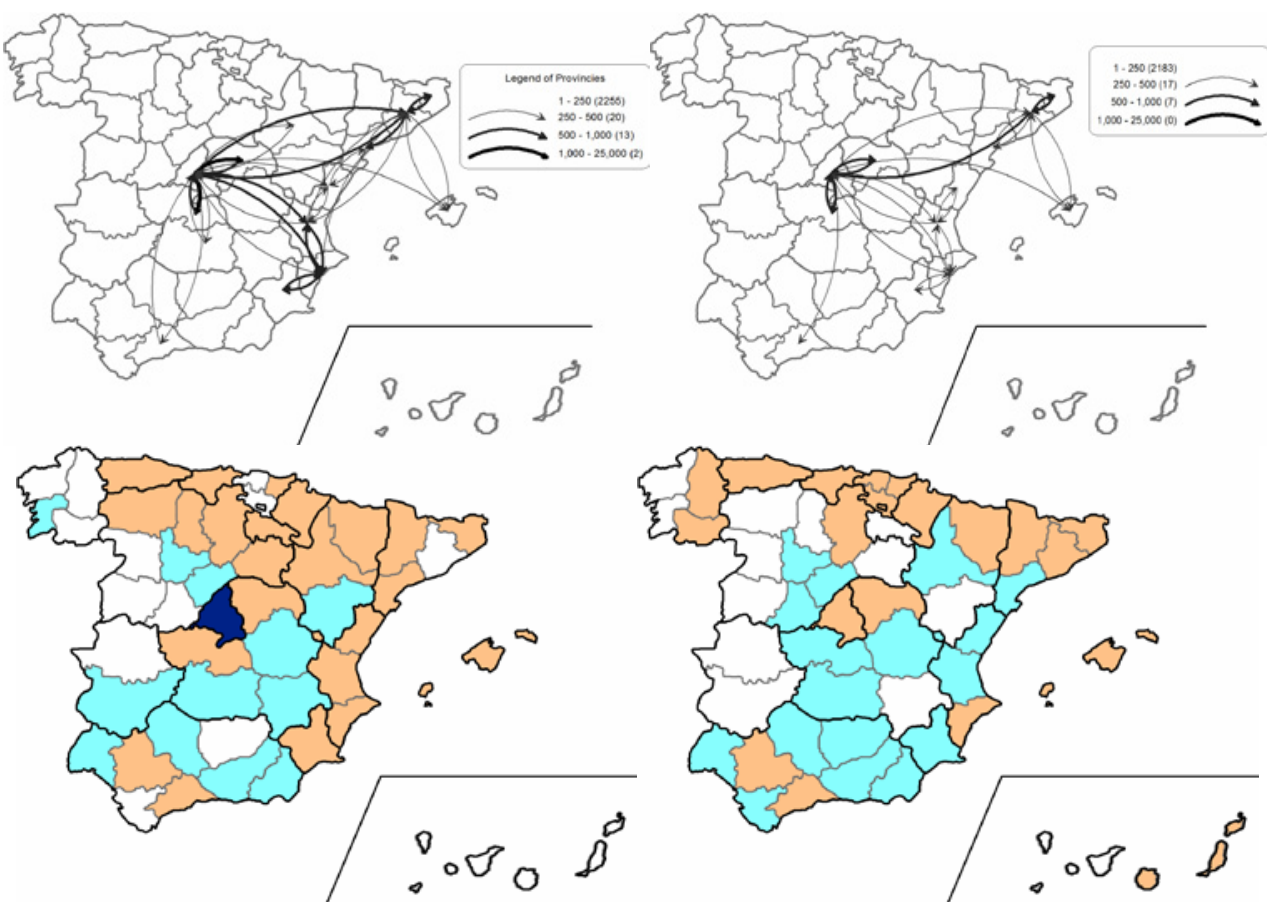


atrayentes ahora expulsan europeos, sea el caso de Murcia, Valencia, Castellón o Tarragona, todas en el litoral mediterráneo, o Zaragoza y Toledo en el interior. Todo el norte de España, en ambos años, presenta saldos migratorios positivos, con más provincias afectadas en 2011.

Figura 10

GRANDES FLUJOS MIGRATORIOS DE AFRICANOS EN ESPAÑA, 2007 Y 2011, Y SALDOS MIGRATORIOS INTER-PROVINCIALES

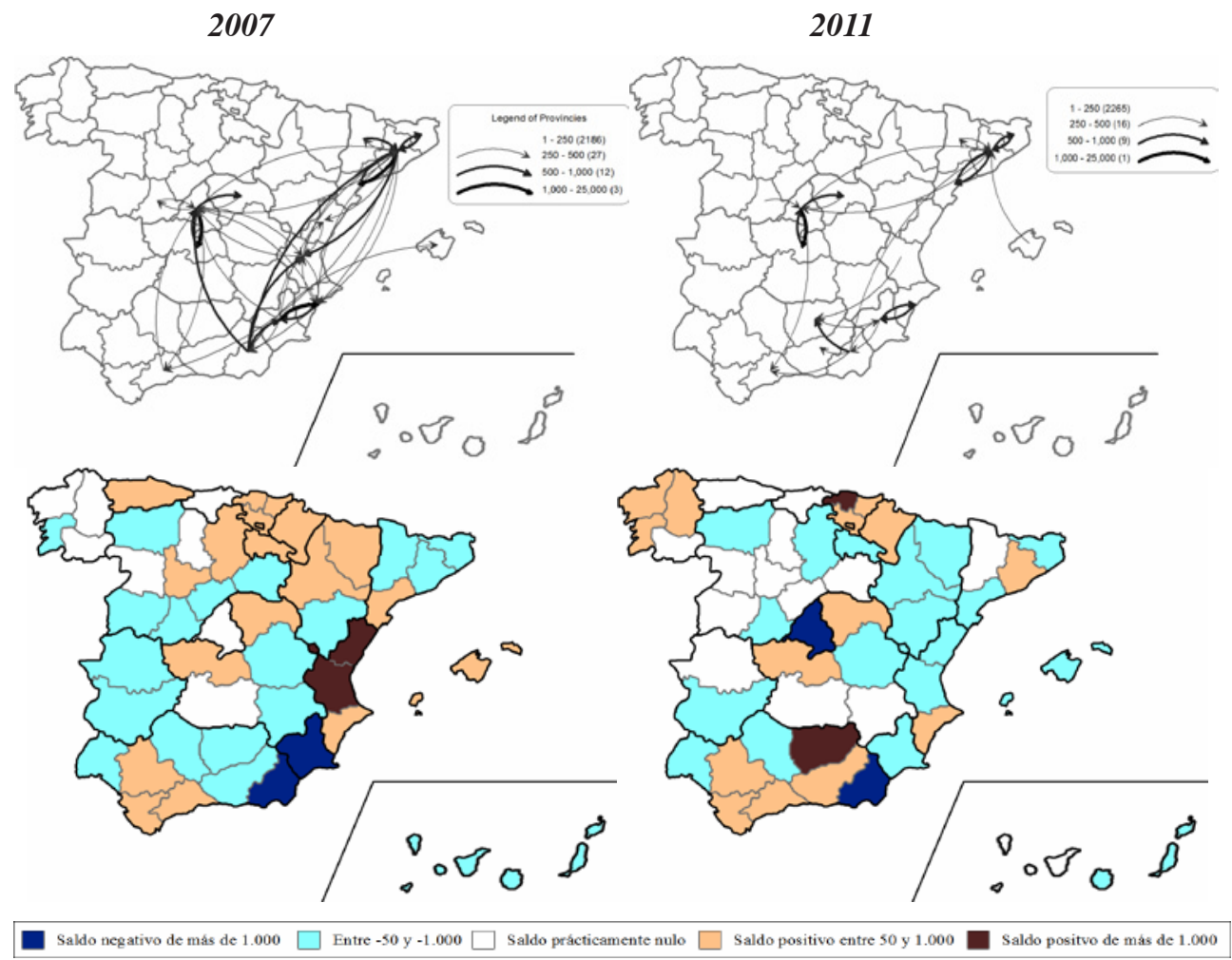

Fuente: Microdatos de la Estadística de Variaciones Residenciales, 2007 y 2011, con datos del INE.

Si centramos la atención en los africanos (figura 10), el descenso de flujos experimentado entre 2007 y 2011 no es muy importante, ya que pasan de 67.224 movimientos a 59.037 (un descenso del 12\%). A pesar de ello, sí que se observan cambios radicales en las pautas territoriales de migración, especialmente si centramos la atención en la Comunidad Valenciana, que de actuar con un efecto de clara atracción migratoria en 2007, pasa a no aparecer entre los principales flujos migratorios, más allá de las salidas en dirección a Jaén (flujo, por otro lado, prácticamente inexistente en 2007). También desaparecen los saltos geográficos que se producían entre Andalucía y Barcelona o Madrid, mientras que la relación entre provincias andaluzas y de éstas con Murcia o Alicante, al contrario, se reafirma. Los movimientos a menor distancia de las dos mayores provincias se mantienen. En cuanto a los saldos migra- 
torios, en este caso los cambios son profundos. En 2007, Almería y Murcia, dos provincias que tradicionalmente funcionaban como puerta de entrada a España, por su actividad laboral en la agricultura, expulsaban un número importante de africanos en dirección a otros sectores laborales y provincias. Valencia y Castellón, en pleno apogeo de la construcción, eran las dos provincias con mayores saldos positivos. En 2011, desaparece la atracción de estas dos últimas zonas, ahora con saldo negativo, y aparecen como nuevas zonas de crecimiento Jaén y Vizcaya, las dos con proporciones de extranjeros bajas, y en el primer caso con una fuerte actividad agraria. Madrid, por su lado, pasa a ser expulsora de africanos, cuando en 2007 tenía un saldo nulo, ya por sí mismo significativo cuando para la mayoría de nacionalidades era un punto de entrada y posterior dispersión. Barcelona, al contrario, pasa de perder africanos a un saldo positivo. También, por último, aparece como significativo el saldo positivo de las provincias gallegas. La colonización de nuevas zonas, y el retorno a la agricultura, son las dos dinámicas que parecen apuntarse en estos flujos.

En tercer lugar, y para los extranjeros con nacionalidades americanas, se observa en la figura 11 un evidente descenso de los flujos migratorios principales entre 2007 y 2011, que refleja el acusado descenso de los 90.764 cambios interprovinciales en 2007 a los 61.604 de 2011 (con un descenso del 32\%). Como en el caso anterior, tampoco aparecen nuevos destinos u orígenes, y en cambio se atenúan los flujos entre Madrid y Andalucía y la Comunidad Valenciana, o de esta última con Barcelona. Es el único caso con relaciones intensas entre Madrid y provincias del litoral cantábrico, aunque en 2011 pierden intensidad las relaciones con Galicia. Únicamente mantienen un nivel de intensidad similar las migraciones entre las dos mayores provincias y entre éstas y las provincias cercanas, lo más similar a la movilidad intra-provincial. El saldo migratorio observado a partir de estas dinámicas coincide, en parte, con lo comentado para otros orígenes, en especial por el cambio de signo de las provincias valencianas, que de fuerte atracción pasan a ser zonas expulsoras. Madrid, en cambio, atenúa su saldo migratorio negativo, cuando tradicionalmente era el principal difusor de americanos en el conjunto de España. Galicia y Euskadi aparecen también como nuevos espacios atractivos para los migrantes americanos, siendo el primer caso significativo, ya que también históricamente ejercía un cierto papel de primera entrada al país y posterior difusión.

En último lugar, al observar el perfil migratorio de los asiáticos encontramos que estos son similares entre ambos años, aunque es el único caso donde aparecen más relaciones significativas en 2011 que en 2007, no en vano se observa un aumento del total de flujos interprovinciales (de 23.651 a 27.464, con un aumento del 16\%). La pauta representada en la figura 12 se caracteriza por intensas relaciones entre Barcelona y Madrid, y de estas con Valencia. Las migraciones a las provincias vecinas ya se muestran en 2007 para Barcelona, y aparecen también en Madrid y Valencia en 2011, así como la relación entre estas dos últimas provincias, que se intensifica. En los saldos, es el caso con menores oscilaciones entre los dos años analizados. Cataluña consolida e intensifica su papel de redistribución, situación a la que por vez primera se añade Madrid. En cambio, y contrastando con el resto de orígenes nacionales, Valencia presenta saldos positivos. El norte cantábrico, igual que en los casos anteriores, destaca por su saldo positivo. Se trata, en comparación con los tres casos anteriores, de una migración interna muy condicionada por la presencia concentrada en el territorio, no en vano, a 1 de enero de 2011, las tres provincias de Madrid, Barcelona y Valencia concentraban el $60 \%$ de los ciudadanos asiáticos residentes en España. 
Figura 11.

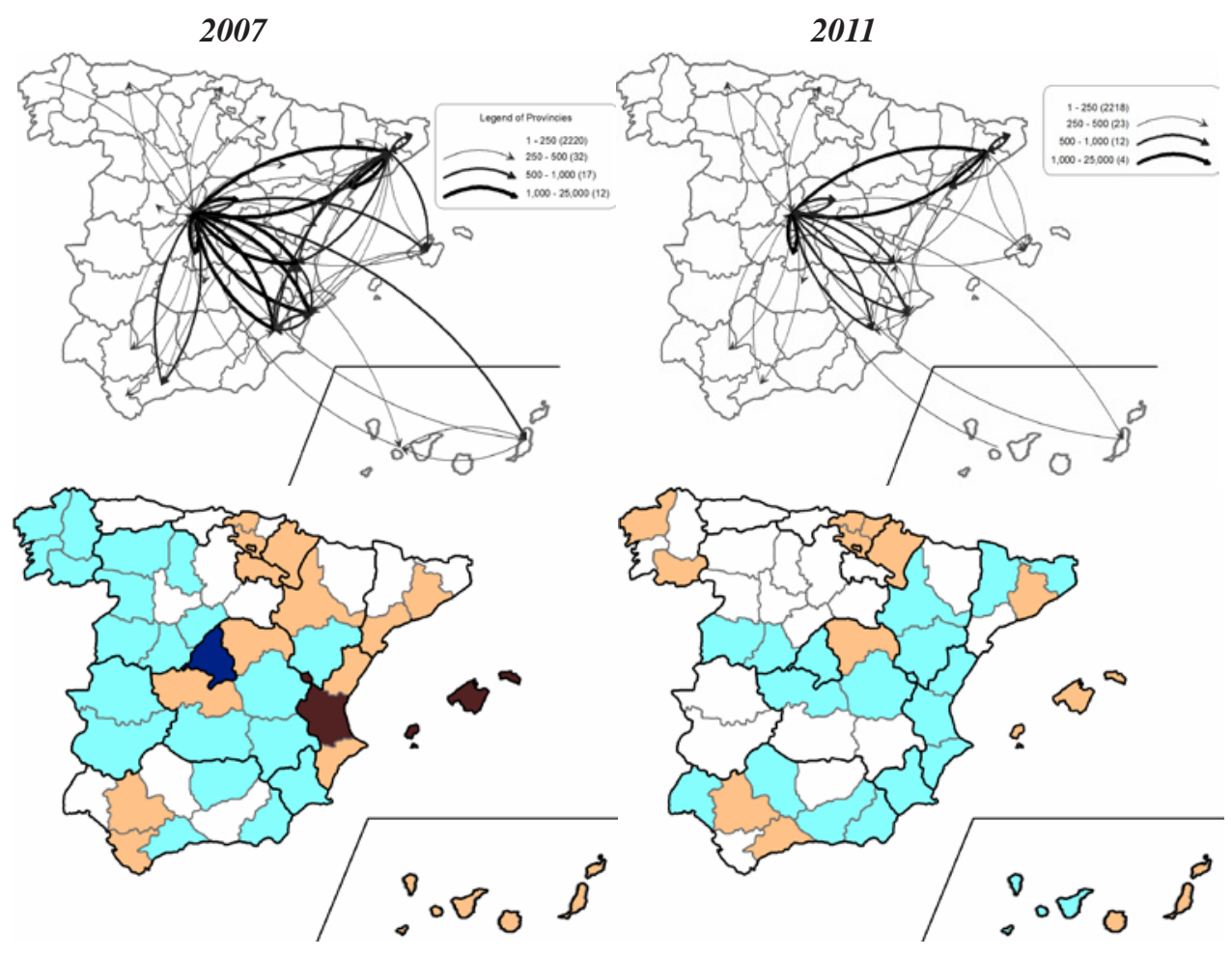

Saldo negativo de más de $1.000 \square$ Entre -50 y $-1.000 \square$ Saldo prácticamente nulo $\square$ Saldo positivo entre 50 y 1.000

Saldo positvo de más de 1.000

Fuente: Microdatos de la Estadística de Variaciones Residenciales, 2007 y 2011, con datos del INE.

En general, tres grandes pautas se repiten en los cuatro casos y caracterizan los cambios acaecidos en la movilidad interna de los extranjeros: 1) el litoral mediterráneo, y en especial las provincias valencianas, pasan de ser zonas con un fuerte impacto de la inmigración interna a exponentes de emigración, todo ello relacionado con el aumento del desempleo en el sector de la construcción. En cambio, 2) zonas otrora redistribuidoras en la actualidad matizan las pérdidas, en lo que se podría pensar como una estrategia de menor movilidad dada la imposibilidad de una mejora significativa de las perspectivas. Esto sucede en provincias muy urbanas (Madrid), o con un fuerte arraigo laboral en la agricultura (Murcia o Almería). Finalmente, 3) las provincias que ahora gozan de mayor atractivo son aquellas con bajos porcentajes de inmigrantes extranjeros (como las de Galicia o País Vasco, siendo Vizcaya la provincia con el saldo positivo más importante en 2011), especialmente si la agricultura -sector relativamente menos castigado por la crisis- es relevante (en Jaén, por ejemplo, se produce el segundo mayor saldo migratorio positivo). 


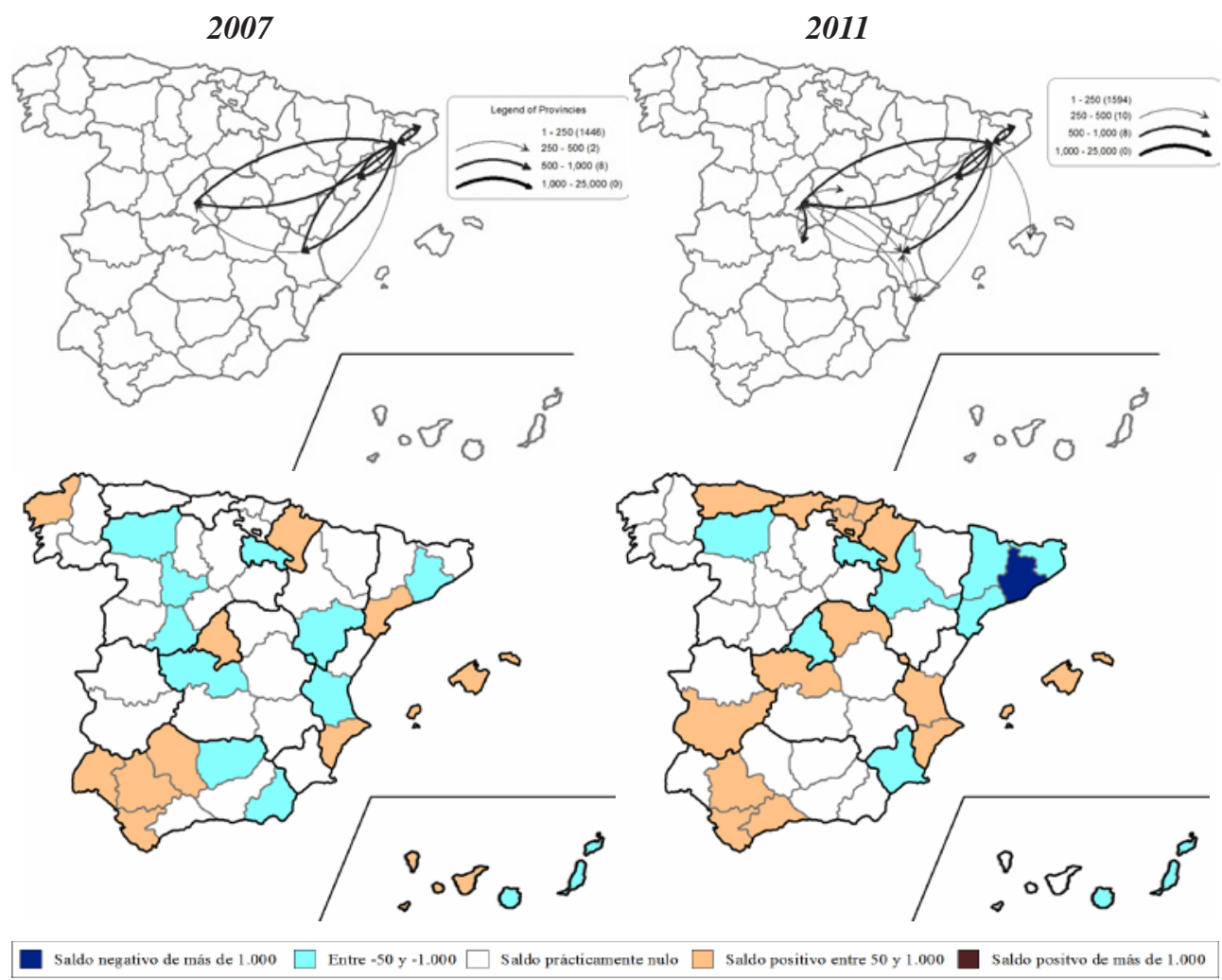

Fuente: Microdatos de la Estadística de Variaciones Residenciales, 2007 y 2011, con datos del INE.

\section{CONCLUSIONES}

Los resultados de la presente investigación demuestran que la situación excepcional que experimentó España en los primeros años del presente siglo en materia migratoria, con la llegada de millones de inmigrantes extranjeros, llegó a su fin a partir de 2008 a raíz de la actual crisis económica, que ha causado una disminución significativa de los flujos migratorios. En efecto, la crisis económica ha dado lugar a una nueva fase caracterizada por la atenuación de los flujos de entrada -si en 2007 llegaron más de 900 mil inmigrantes extranjeros a España, en 2012 esta cifra se ha reducido a menos de 340 mil-, confirmando de esta manera la hipótesis de Martin (2009) en el sentido de que la duración de la crisis no sólo acabaría reduciendo los flujos de entrada en España sino también la salida de una parte de los extranjeros que residían en nuestro país, al tener que enfrentarse a menores expectativas laborales. Y ello desmentiría, al menos para la mayoría de colectivos extranjeros, la hipótesis expuesta 
por Fielding (2010) de que en la actual fase del capitalismo postfordista, y en países con un mercado de trabajo dual, los inmigrantes se adaptarían mejor a la crisis que los trabajadores autóctonos. Quizás el hecho que la duración y la dureza de la crisis haya obligado a la mano de obra española a volver a ocupar nichos laborales que, durante la fase de expansión económica, había dejado en manos de los extranjeros, sea una explicación para esta evolución.

Pero, además, la recesión económica ha causado una reducción de la movilidad interna de los extranjeros -quienes, una vez en nuestro país, cambian menos de municipio de residencia que lo que hacían antes del inicio de la crisis-, cumpliendo la pauta señalada por Courgeau (1985). Esta disminución ha sido superior a la experimentada por la población autóctona, aunque los extranjeros siguen siendo mucho más móviles que los españoles. Por último, la crisis habría causado también una modificación de las pautas espaciales de redistribución interna de los inmigrantes, provocando, por ejemplo, ciertas modificaciones en las provincias de origen y destino de sus cambios de residencia interprovinciales, de manera semejante a lo que Recaño y Cabré (2003) habían mostrado al analizar el impacto que crisis anteriores habían tenido en las pautas de migración interna de la población española.

Hasta 2008, la aceleración de la llegada de inmigrantes, junto con la inestabilidad residencial que caracterizó los primeros años de asentamiento, provocó unas altas tasas de migración interna dentro de España. El año 2007 fue el año en el que más inmigrantes extranjeros cambiaron de municipio de residencia, cerca de 540 mil (en comparación, en 2001 sólo unos 100 mil cambios de residencia fueron protagonizados por extranjeros), de los cuales, unos 290 mil de ellos fueron entre municipios de la misma provincia, mientras que unos 250 mil fueron cambios entre municipios de distintas provincias. Como consecuencia de la crisis, estas migraciones internas protagonizadas por extranjeros han reducido su número, siendo en 2011 algo menos de 440 mil, de las cuales unas 250 mil entre municipios de la misma provincia y unas 200 mil, migraciones interprovinciales.

Pese a la crisis, los extranjeros, con 77 migraciones internas por cada mil habitantes de dicho origen, cambiaron de residencia en 2011 muchas más veces que los autóctonos, con sólo 29 cambios de residencia por cada mil españoles. Entre los extranjeros, también hay diferencias de movilidad interna según el origen continental: los asiáticos son los que más cambian de residencia dentro de España, seguidos por los africanos (que son principalmente marroquíes) y los americanos (mayoritariamente de países iberoamericanos). Los más estables, con una tasas de migración interna similares a los de los españoles, son los nacionales de países de la antigua Unión Europea de 15 estados miembros (Europa occidental). Muchos de ellos son jubilados que se han establecido en España por razones residenciales y, por ello, su movilidad interna ha sido la que ha seguido una pauta más estable, menos afectada por la crisis económica. Bastante más móviles que los anteriores son los europeos del «resto de Europa», es decir, de los nuevos estados miembros y de los países europeos no comunitarios. Se trata de un colectivo - con mucha presencia de búlgaros y, sobre todo, de rumanos- que ha emigrado a nuestro país por razones labores y que tuvieron una fuerte presencia en el sector de la construcción en los años del boom inmobiliario.

El efecto de la crisis se nota en la mayor disminución de los desplazamientos de largo alcance, mientras se mantienen mejor aquéllos entre provincias colindantes. Es decir, que determinadas provincias como Madrid, que ejercen de puerta de entrada de los inmigrantes extranjeros para después redistribuirlos hacia otras provincias españoles (por lo que tiene un 
saldo de migración interna negativo), han visto que han bajado significativamente la magnitud de dichos flujos, tanto por el menor aporte directo del extranjero -menor llegada de inmigrantes-, como por una reducción significativa de la movilidad interprovincial, debido a que las menores perspectivas laborales desincentiva a muchos inmigrantes de cambiar de residencia. Esta situación de caída de los flujos de salida se reproduce en provincias con un fuerte peso agrícola como Murcia o Almería, que eran tradicionalmente expulsoras hacia otras provincias de migrantes extranjeros que se habían insertado en primer lugar en el mercado de trabajo español trabajando en la agricultura, sector que, en épocas de crisis, puede ejercer como refugio. Esta función del sector agrario puede explicar la situación de provincias andaluzas como Jaén, que sorprendentemente es, en el año 2011, la segunda provincia con un saldo migratorio positivo más importante. También el litoral cantábrico menos afectado por la explosión de la burbuja inmobiliaria- aparece como receptor de flujos internos, en una incipiente dinámica de reequilibrio de los extranjeros residentes en España vía migración interna.

Por lo tanto, no sólo hay menos migraciones internas debido a la crisis, sino también una modificación de sus patrones espaciales. En efecto, respecto al origen y destino de los flujos migratorios internos protagonizados por extranjeros, es destacable el cambio de función experimentado por algunas provincias, que de receptoras netas pasan a ser emisoras, y viceversa. Los mayores cambios se observan en las provincias de la Comunidad Valenciana y mediterráneas colindantes (Tarragona, Murcia), justamente donde se observaban los saldos migratorios internos más positivos en el periodo de expansión económica, y que ahora «expulsan» a los migrantes extranjeros hacia otras provincias (es decir, tienen saldos por migración interna negativos), variación que debe relacionarse con los efectos de la crisis económica sobre el mercado laboral, particularmente sobre la construcción, donde muchos inmigrantes masculinos tenían su puesto de trabajo. Por otra parte, y aunque de forma lenta, se observa una continua redistribución de la población extranjera hacia aquellas provincias donde el peso de los extranjeros se encontraba, durante el periodo expansivo, por debajo de la media, como es el caso de toda la cornisa cantábrica y determinadas provincias interiores con un componente agrario más marcado. Todas ellas, aunque con flujos migratorios internos de poca magnitud, pasan a tener a saldos positivos, convirtiéndose, de manera modesta, en los «nuevos Eldorados» hacia los que se dirigen los migrantes extranjeros en busca puestos de trabajo, menos escasos allí que en otras provincias.

En definitiva, el menor número de migraciones (tanto internacionales como internas), la redistribución de los migrantes extranjeros desde las provincias más afectadas por el pinchazo de la burbuja inmobiliaria hacia las provincias que cuentan con porcentajes de extranjeros más bajos, y una cierta estabilidad -o fijación- residencial en comparación a la etapa anterior a 2008, parecen ser los efectos más significativos de la crisis en materia migratoria, aunque su profundidad e impacto sobre la población extranjera hacen prever nuevos cambios en los años futuros. A pesar de ello, los niveles actuales de entradas y salidas de migrantes extranjeros, y de circulación migratoria interna de éstos, reflejan un país que, en materia migratoria, ha cambiado enormemente respecto a la situación existente a mediados de la década de los noventa. En la actualidad, y pese a la mala coyuntura económica, los flujos migratorios de España son los característicos de un país con un stock importante y consolidado de residentes extranjeros. 


\section{REFERENCIAS}

ABELLA, M. y DUCANES, G. (2009): Technical note on the effect of the global economic crisis on Asian migrant workers and governments' responses. Bangkok, ILO Regional Office for Asia and the Pacific.

AJA, E., ARANGO, J. y OLIVER, J. (Dir.) (2010): La inmigración en tiempos de crisis. Anuario de la inmigración en España 2009. Barcelona, CIDOB.

AWAD, I. (2009): The Global Economic Crisis and Migrant Workers: Impact and Response. Geneva, International Labour Office.

BAYONA, J. y GIL-ALONSO, F. (2012): «Suburbanisation and international immigration: The case of the Barcelona Metropolitan Region (1998-2009)» en Tijdschrift voor economische en sociale geografie / Journal of Economic and Social Geography, Vol. 103, $n^{o}$ 3, 312-332.

BAYONA, J. y GIL-ALONSO, F. (2013): «Is foreign immigration the solution to rural depopulation? The case of Catalonia (1996-2009)» en Sociologia Ruralis, 53 (1), 26-51.

BAYONA, J. y LÓPEZ-GAY, A. (2011): «Concentración, segregación y movilidad residencial de los extranjeros en Barcelona» en Documents d'Anàlisi Geogràfica, no 57 (3), 381-412.

BÉLANGER, A. (1993): «La migration interprovinciale des personnes nées à l'étranger, Canada, 1981-1986», en Cahiers Québécois de Démographie, 22- 1, 153-78

CAPOTE, A. (2012): «Inmigración extranjera en la provincia de Córdoba: destino secundario de los inmigrados marroquíes en Andalucía» en Scripta Nova. vol. XVI, no 419.

CASTLES, S. (2009): Migration and the Global Financial Crisis: A Virtual Symposium. Update 1.A: An Overview.

CASTLES, S. (2011): «Migration, crisis, and the global labour market» en Globalizations, June 2011, vol. 8(3), 311-324.

CASTLES, S. y MILLER, M.J. (2010): Migration and the Global Economic Crisis: One Year On. Update 1.L.

COURGEAU, D. (1985): «Interaction between Spatial Mobility, Family and Career LifeCycle: A French Survey» en European Sociological Review, vol. 1(2), p. 139-162.

DOBSON, J., LATHAM, A. y SALT, J. (2009): On the Move? Labour Migration in Times of Recession. London, Policy Network Papers.

DOMINGO, A. y RECAÑO, J. (2007): «Perfil demográfico de la inmigración extranjera en España» en AJA, E., ARANGO, J. (Eds). La inmigración en España en 2006. Anuario de inmigración y políticas de inmigración. Barcelona, Fundación CIDOB, 20-43.

DOMINGO,A. y SABATER, A. (2010): «El empadronamiento de la población extranjera en los municipios catalanes de 2004 a 2008» en Scripta Nova. vol. XIV, n ${ }^{\circ} 344$.

FIELDING, T. (2010): Migration in a Time of Crisis: A simple conceptual framework applied to East Asian migrations, Working Paper, n. 63, Sussex Centre for Migration Research.

FINNEY, N. y SIMPSON, L. (2009): «Population Dynamics: The Roles of Natural Change and Migration in Producing the Ethnic Mosaic» en Journal of Ethnic and Migration Studies, 35(9) 1479-1496.

FIX, M., PAPADEMETRIOU, D.G., BATALOVA, J., TERRAZAS, A., YI-YING LIU, S., MITTLESTADT, M. (2009): Migration and the Global Recession. Washington DC, Migration Policy Institute. 
FREY, W.H. (1996): «Immigration, domestic migration, and demographic balkanization in America: new evidence for the 1990s» en Population and Development Review, $\mathrm{n}^{\circ} 22$ (4), 741-763.

GARCÍA-COLL, A. (2005): «Migraciones interiores y transformaciones territoriales» en Papeles de Economía Española, $\mathrm{n}^{\mathrm{0}}$ 104, 76-91.

GARCÍA-COLL, A. (2009): «Migraciones interiores y transformaciones territoriales» en PONS, J.J. et al. (ed.) Territorio y movilidad interior de la población en España. Pamplona: Ediciones Universidad de Navarra, 13-40.

GHOSH, J. (2009): Will the Crisis Reverse Global Migration?, globalpolicy.org

GIL-ALONSO, F., BAYONA, J. y PUJADAS, I. (2013): «From boom to crash: Spanish urban areas in a decade of changes (2001-2011)» en European Urban and Regional Studies. DOI: 10.1177/0969776413498762.

I.N.E. (2013): Cifras de Población a 1 de enero de 2013 - Estadística de Migraciones 2012. Datos provisionales. Madrid, Instituto Nacional de Estadística, Notas de prensa, 25 de junio de 2013 (actualizada el 8 de julio de 2013).

KING, R., FIELDING, A. y BLACK, R. (1997): «The international migration turnaround in southern Europe» en R. KING y R. BLACK. (Eds.) Southern Europe and the New Immigrations. Brighton, Sussex Academic Press, 1-25.

MARCU, S. y GOMEZ, I. (2010): «La movilidad de los inmigrantes rumanos en la Comunidad de Madrid: Pautas de asentamiento y retorno» en Scripta Nova. Revista Electrónica de Geografía y Ciencias Sociales. vol. XIV, $\mathrm{n}^{\circ} 341$.

MARTÍ, M. y RÓDENAS, C. (2006): «Reinterpretando el crecimiento de la movilidad de España: la población extranjera y las migraciones repetidas» en Cuadernos Aragoneses de Economía, vol. 16(1), 37-59.

MARTÍ, M. y RÓDENAS, C. (2012): «Reemigrar en España: una aproximación a sus determinantes» en Investigaciones Regionales, $\mathrm{n}^{\circ} 22,105-128$.

MARTIN, P. (2009): «Recession and Migration: A new era for labour migration» en International Migration Review, vol. 43, $\mathrm{n}^{\circ} 3,671-691$.

NACIONES UNIDAS (2013): «The number of international migrants worldwide reaches 232 million» en Population Facts, n $^{\circ} 2013 / 2$

NEWBOLD, K.B., (1996): «Internal migration of the foreign-born in Canada» en International Migration Review, 30(3), 728-747.

PAPADEMETRIOU, D. y TERRAZAS, A. (2009): Immigrants and the Current Economic Crisis. Washington DC, Migration Policy Institute.

POZO, E. y GARCÍA, J.C. (2009): «Inmigración y cambio demográfico en la región metropolitana madrileña entre 1996 y 2006» en Anales de Geografía, 29 (1), 111-138.

PUMARES, P. (2003): «La inmigración en España: perspectivas desde el territorio» en AUBARELL, G. (Dir.), Perspectivas de la inmigración en España, Barcelona, Icaria, 177-204.

PUMARES, P. (2005): «Distribución territorial y movilidad interprovincial de la población marroquí en España» en L. DI COMITE, V. RODRÍGUEZ y S. GIRONE (eds.), Quaderni 32. Sviluppo demografico e mobilità territoriale delle popolazioni nell'area del Mediterraneo: Italia e Spagna, due paesi a confronto (Bari: Caccuci Editore), 203-230. 
PUMARES, P., GARCÍA, A. y ASENSIO, A. (2006): La movilidad laboral y geográfica de la población extranjera en España. Madrid, OPI, Ministerio de Trabajo y Asuntos Sociales, Documentos, $\mathrm{n}^{\circ}$ 10, 217.

RATHA, D., MOHAPATRA, S., SILWAL, A. (2009): Migration and Remittance Trends 2009, Migration and Development Brief 11, Washington DC, World Bank.

RATHA, D., MOHAPATRA, S., SILWAL, A. (2010): Outlook for Remittance Flows 201011 , Migration and Development Brief 12, Washington DC, World Bank.

RECAÑO, J. (2002): «La movilidad geográfica de la población extranjera en España: un fenómeno emergente» en Cuadernos de Geografía, n ${ }^{\circ}$ 72, 135-156.

RECAÑO, J. y CABRÉ, A. (2003): «Migraciones Interregionales y ciclos económicos en España (1988-2001) » en Papeles de Geografía, 37, p.179-197.

RECAÑO, J. y DOMINGO, A. (2006): «Evolución de la distribución territorial y la movilidad geográfica de la población extranjera en España» en AJA, E. y ARANGO, J. (eds.) Veinte años de inmigración en España: perspectiva jurídica y sociológica (1985-2004), Barcelona, CIDOB, 223-256.

RECAÑO, J. y DE MIGUEL, V. (2012): «The Internal Migration of foreign-born Population in Southern Europe: Demographic Patterns and Individual Determinants» en FINNEY, N. y CATNEY, G. (Ed.) Minority Internal Migration in Europe, Ashgate, International Population Studies, 239-262.

REHER, D. y SILVESTRE, J. (2011): «Internal Migration Patterns of Foreign-Born Immigrants in Spain. A study based on the National Immigrant Survey (ENI-2007)» en RISRevista Internacional de Sociología, Monográfico 1, 167-188.

REYNERI, E. (2009): «Immigration and the Economic Crisis in Western Europe», VI Congreso de la Inmigración en España, La Coruña, 17-19 septiembre.

ROGERS, A. y HENNING, S. (1999): «The internal migration patterns of the foreign-born and native-born populations in the United States: 1975-80 and 1985-90» en International Migration Review, $\mathrm{n}^{\circ}$ 33-2, 403-429.

SABATER, A., BAYONA, J. y DOMINGO, A. (2012): «Internal migration and Residential patterns across Spain after unprecedented international migration» en FINNEY, N. y CATNEY, G. (Ed.) Minority Internal Migration in Europe, Surrey, Ashgate Publishing, International Population Studies Series. Cap. XIV, p. 293-311.

TROVATO, F. (1988): «The interurban mobility of the foreign born in Canada, 1976-81» en International Migration Review, $\mathrm{n}^{\circ}$ 22(3), 59-86.

VIDAL-COSO, E. y GIL-ALONSO, F. (2013): «La destrucción de empleo de migrantes y españoles (2007-2012): Factores demográficos, sectoriales y territoriales». Comunicación presentada en el XI Congreso Español de Sociología. «Crisis y cambio: propuestas desde la Sociología», Madrid, 10-12 de julio.

VIRUELA, R. (2010): «Movilidad geográfica de los rumanos (Estructura territorial de las migraciones interiores en España)» en Empiria, 19, 157-181.

ZORLU, A. y LATTEN, J. (2009): «Ethnic Sorting in The Netherlands» en Urban Studies, 46(9), 1899-1923. 
